"This is the peer reviewed version of the following article: Topics in Organometallic Chemistry, vol. 53, Ed. XiaoBing Lu, 2016, 2, 39-71, which has been published in final form at https://doi.org/10.1007/3418 2015 94. This article may be used for non-commercial purposes in accordance with the Terms and Conditions for Self-Archiving published by Springer at https://link.springer.com/chapter/10.1007\%2F3418 2015 94." 


\section{Metal complexes catalyzed cyclization with $\mathrm{CO}_{2}$}

Jeroen Rintjema, Leticia Peña Carrodeguas, Victor Laserna, Sergio Sopeña, Arjan W. Kleij*

Institute of Chemical Research of Catalonia (ICIQ), Av. Països Catalans 16, 43007 - Tarragona (Spain)

Tel: $+34-977920247$

Fax: $+34-977920828$

E-mail: $\underline{\text { akleij@iciq.es }}$

Book chapter for: Topics in Organometallic Chemistry (3418)

Volume title: $\quad$ Carbon Dioxide and Organometallics

Editor: $\quad$ Prof. Dr. Xiao-Bing Lu, State Key Laboratory of Fine Chemicals, Dalian University of Technology, E321 West Campus, 2 Linggong Rd., Dalian 116024, China xbLu@dlut.edu.cn or Lxb-1999@163.com 


\section{Contents:}

1. Introduction

2. Binary Type Catalysts

3. Bifunctional Catalysts

4. Addition of Carbon Dioxide to Double and Triple Bonds

5. Synthesis of Oxazolidinones Using $\mathrm{CO}_{2}$ and Metal Catalysts

5.1 Insertion of $\mathrm{CO}_{2}$ into an aziridine moiety

$5.2 \mathrm{CO}_{2}$ coupling reactions with aminoalcohols and propargylic reagents

6. Synthesis of Ureas

7. Formation of Lactones

8. Outlook

9. References 


\begin{abstract}
:
This chapter describes in general terms the catalytic methodology that has been made available for the use of carbon dioxide $\left(\mathrm{CO}_{2}\right)$ in cyclization reactions that incorporate an intact $\mathrm{CO}_{2}$ fragment without changing the formal oxidation state of the carbon center. The major focus of this chapter will be on the most successful organometallic/inorganic complexes that have been used as catalyst systems throughout the last decade, and the preferred ligand frameworks leading to elevated reactivity and/or selectivity behavior in $\mathrm{CO}_{2}$ coupling reactions. Attention will be especially given to homogeneous catalyst systems as they have proven to be more versatile in $\mathrm{CO}_{2}$ conversion catalysis, and often have modular characteristics that allow for optimization of structure-activity relationships. The most important reactions that have been studied in the current context are designated $\mathrm{CO}_{2}$ "addition" reactions to small molecule heterocycles such as epoxides and aziridines, though more recently other coupling partners such as diamines, dialcohols and amino-nitriles have further advanced the use of $\mathrm{CO}_{2}$ in organic synthesis providing access to a wider range of structures. This chapter will serve to demonstrate the utility of $\mathrm{CO}_{2}$ as a carbon reagent in the catalytic formation of the most prominent organic structures using cyclization strategies specifically.
\end{abstract}




\section{Introduction}

Carbon dioxide $\left(\mathrm{CO}_{2}\right)$ has recently emerged as an attractive carbon reagent that may partially substitute fossil fuels in synthetic strategies towards a wide range of organic structures. ${ }^{[1-3]}$ It represents a cheap and abundant carbon building block but its kinetic stability is a challenge that can only be addressed by devising efficient catalytic processes and ditto catalyst systems. ${ }^{[4,5]}$ Therefore, a lot of focus in the scientific communities has been on the design of suitable catalyst systems than can potentially combine modular features, high reactivity and selectivity, and amplified substrate scope that would serve to increase the synthetic application of $\mathrm{CO}_{2}$ as a building block. ${ }^{[6,7]}$ The most widely studied reactions include the formation of polycarbonate polymers, ${ }^{[8]}$ the formation of carboxylated scaffolds ${ }^{[9]}$ and the coupling between epoxides/oxetanes/aziridines ${ }^{[10-12]}$ leading to various heterocyclic structures with synthetic, pharmaceutical or solventderived application potential.

The latter category of organic molecules is particularly interesting for a number of reasons. Cyclic carbonates, derived from epoxide/ $\mathrm{CO}_{2}$ couplings, are organic compounds that possess very interesting properties such as low evaporation rates, low toxicity and biodegradability. ${ }^{[13]}$ These properties make them useful for industrial or scientific applications such as aprotic high-boiling polar solvents, electrolytes for lithium-ion batteries, precursors for polymeric materials, fine chemical intermediates, fuel additives, plastic materials and agricultural chemicals. ${ }^{[14]}$ One of the most important examples in this respect is propylene carbonate which is produced at an industrial level. Apart from their industrial applications, cyclic carbonate structures also appear in various natural compounds present in fungi, bacteria and/or plants. Some examples of such cyclic carbonate-containing natural products include Hololeucin and Cytosporin $\mathrm{E}^{[15]}$ which are shown in Figure 1.

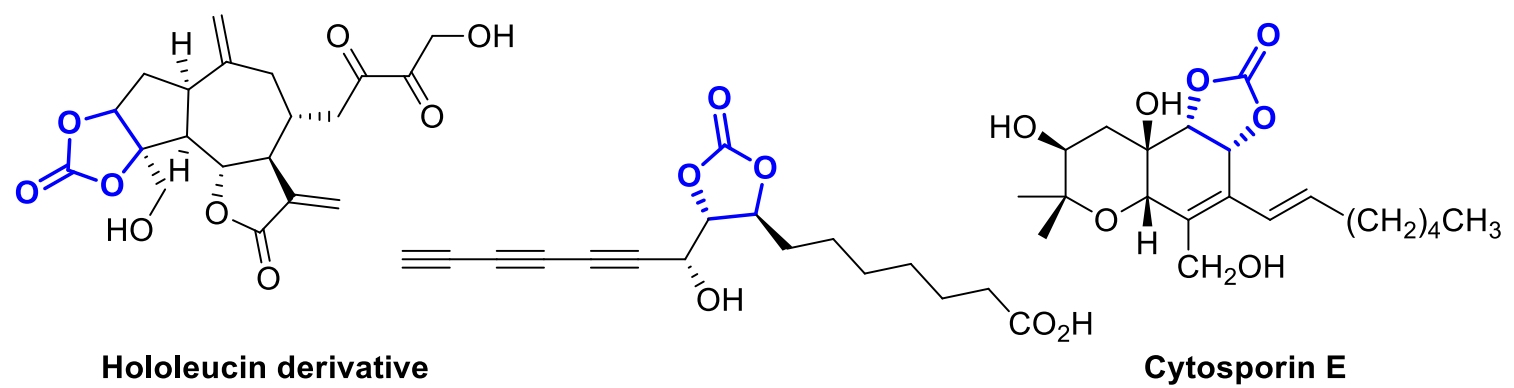

Antibiotic L-660,331

Figure 1. Some examples of cyclic carbonate-containing natural compounds found in plants, fungi and bacteria. Note that the carbonate unit is highlighted in blue.

In industry, cyclic carbonates are mostly obtained by environmentally hazardous methodologies which involve the use of phosgene. Although phosgene is a versatile 
reagent widely used in the production of plastics and pesticides, it is also a toxic, corrosive and difficult to handle gas. Exposure to phosgene may have adverse consequences to health and therefore its use is not desirable. For these reasons, its application in industrial large-scale synthesis should be avoided and a lot of effort has been put into finding suitable alternatives. In the last decades greener routes for the synthesis of cyclic carbonates such as those based on the use of carbon dioxide have generated great interest. This chemistry has also been amplified to similar types of coupling reactions that involve aziridines and oxetanes. In general, the development of low toxic, cost-effective and highly active catalytic systems has been a major milestone providing attractive solutions for the chemical fixation of $\mathrm{CO}_{2}$ producing organic matter with an increased value.

With the rise of green chemistry, the number of environmentally more friendly processes towards $\mathrm{CO}_{2}$-based heterocyclic structures and alike has been increasing at a rapid pace. Some of this new greener processes involve the use of ionic liquids, ${ }^{[16]}$ organocatalysts, ${ }^{[17-}$ 22] supercritical $\mathrm{CO}_{2}{ }^{[23,24]}$ or metal-based photocatalysts ${ }^{[25,26]}$ although the most commonly used catalysis methodology for the synthesis of these compounds is the metalcatalyzed "cycloaddition" of carbon dioxide to small heterocyclic substrates better referred to as $\mathrm{CO}_{2} /$ substrate couplings. The use of ring-strained substrates thermodynamically favors the formation of the heterocyclic compounds. When using oxiranes (epoxides) as substrates, five-membered cyclic carbonates are obtained and in a similar way six-membered cyclic carbonates are derived from oxetanes (Scheme). The conversion of oxetanes into six-membered carbonates has been much less studied probably due to their lower intrinsic reactivity and more limited accessibility compared to oxiranes. In the conversion of epoxides, the cyclic carbonates are the thermodynamic products with possible competitive formation of polycarbonates, which are the kinetic products. The selectivity towards polycarbonates or cyclic carbonates generally depends on the catalyst, additives, temperature, pressure and epoxide concentration. ${ }^{[27]}$

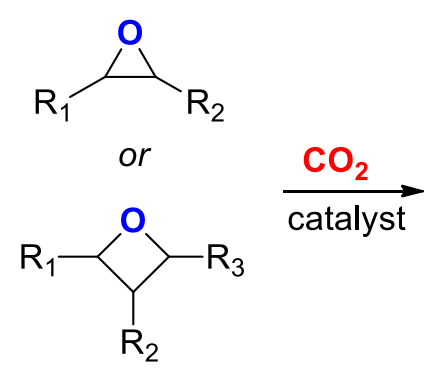<smiles>[R]C1OC(=O)OC1[R2]</smiles>

Scheme 1. Cyclic carbonate synthesis from oxiranes and oxetanes. 
During the last 30 years, the homogeneously catalyzed formation of cyclic carbonates through $\mathrm{CO}_{2}$ addition chemistry has been a thoroughly investigated topic and many catalytic systems have appeared that address different process features such as chemoselectivity, enantio-selectivity, sustainability, reactivity and substrate scope. In the next sections, a detailed description of these classes of catalyst systems will be given together with their specifics. As such, a comprehensive overview of the literature is avoided, as the intention is to showcase the most important developments in this area of $\mathrm{CO}_{2}$ catalysis.

PORPHYRINS

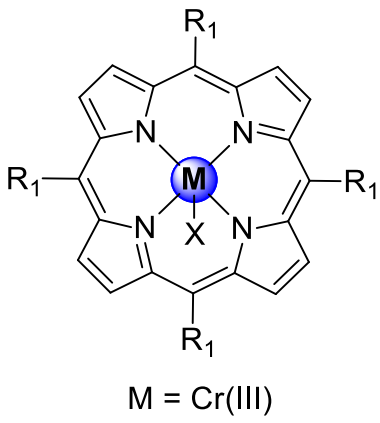

AMINOTRISPHENOLATES

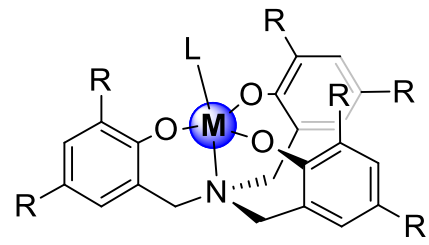

$M=\operatorname{Al}(I I I), F e(I I I)$
PHTALOCYANINES

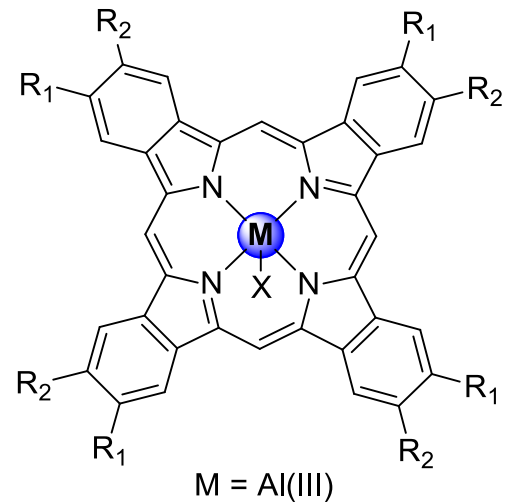

SALENS

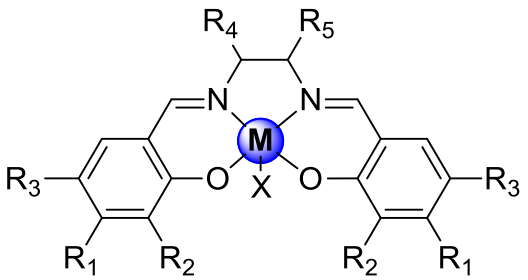

$M=A l(I I I), \operatorname{Cr}(I I I), \operatorname{Co}(I I, I I I), M n(I I I)$, Sn (II, IV), Ru (II, III)

Figure 2. Typically used metal complexes derived from porphyrins, phtalocyanines, aminotrisphenolates and salens used as catalyst for the synthesis of cyclic carbonates from oxiranes and oxetanes. The $X$ usually refers to a halide.

\section{Binary Type Catalysts}

Undoubtedly, the most popular catalyst type in the context of $\mathrm{CO}_{2}$ addition catalysis is the binary catalyst system. These systems usually consist of a metal complex acting as a (Lewis acid) activator in the presence of amines or ammonium/phosphonium halides as nucleophilic co-catalysts. It is known that metal catalyst complexes combining both a Lewis acidic and basic function effectively couple carbon dioxide and epoxides to afford cyclic carbonates. ${ }^{[28]}$ In 2002, Caló and coworkers ${ }^{[29]}$ reported on the cyclic carbonate synthesis from carbon dioxide and oxiranes using tetrabutylammonium halides as solvents and/or catalysts under atmospheric pressure of $\mathrm{CO}_{2}$. Alternatively, Lau and coworkers $^{[22]}$ reported on the coupling of carbon dioxide and oxiranes catalyzed by bis(triphenylphosphine)imine (PPN) salts to yield cyclic carbonates. These two 
contributions can be considered a milestone in the field, as these PPN and tetrabutylammonium salts are the most employed salts as cocatalysts. However, the use of metal complexes as substrate activators has resulted in far better catalyst systems enabling significantly higher reactivities and selectivities.

Important advances in this area have been obtained by using complexes based on transition/main group metals such as aluminium, cobalt, or iron with ligand frameworks such as porphyrins, ${ }^{[25]}$ phtalocyanines, ${ }^{[30-32]}$ triphenolates ${ }^{[33]}$ and salens (Figure 2). ${ }^{[34-39]}$ Metalloporphyrinates and metallophtalocyanines are compounds that have been typically used as dyes, functional materials and oxidation catalysts. These metal complexes possess high activity towards the coupling reaction between carbon dioxide and oxiranes allowing the formation of linear or cyclic carbonates, and polycarbonates in high yields. However, typically high reaction temperatures are required for efficient catalytic turnover making the systems of lesser value from a sustainability point of view (Scheme).
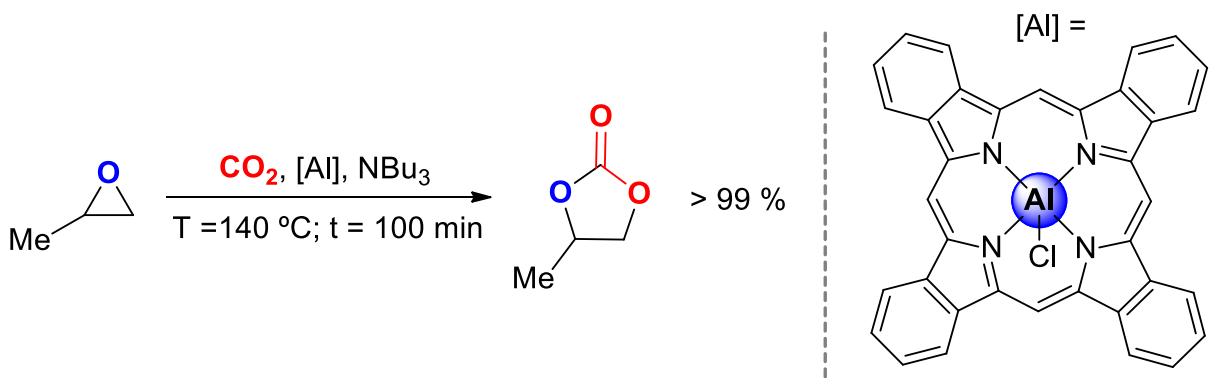

\section{Scheme 2. Example of a binary catalyst system formed by an aluminium phtalocyanine complex and tributylamine as nucleophilic co-catalyst in the coupling reaction between propylene oxide and carbon dioxide.}

Metal-salen complexes are the most versatile and popular catalysts applied in the reactions between carbon dioxide and oxiranes. ${ }^{[6]}$ One of the reasons for their popularity is the ease of synthesis in comparison with porphyrins and the fact that the condensation of the diamine and the aldehyde precursors allows for a straightforward modulation of the steric and electronic properties of the metal catalyst. ${ }^{[40]}$ The large number of possible structural combinations has enabled the development of a large number of catalysts based on salphens, binaphtyl derived salens and bimetallic salen complexes (Figure) among others. These metal complexes require, as is the case for porphyrin and phtalocyanine metal-based catalysts, an additional nucleophilic co-catalyst to attain high activity (i.e., binary type catalyst).

Jacobsen and co-workers discovered that $\mathrm{Co}$ (III)salens are highly efficient catalysts for the hydrolytic kinetic resolution of ( $\mathrm{rac}$-epoxides using water as the nucleophile. ${ }^{[41]}$ The formation of cyclic carbonates shows large resemblance with this seminal work of Jacobsen as the ring-opening of an oxirane by a nucleophile/Lewis base is requisite to react it with $\mathrm{CO}_{2}$. In the absence of any co-catalytic nucleophile, high activity cannot be obtained and only trace amounts of the cyclic carbonate are formed. Generally the activity 
of a binary catalytic system can be increased with increasing basicity of the Lewis base. In the case of halide nucleophiles, also the leaving group ability and size features are important parameters controlling the reactivity.

SALEN

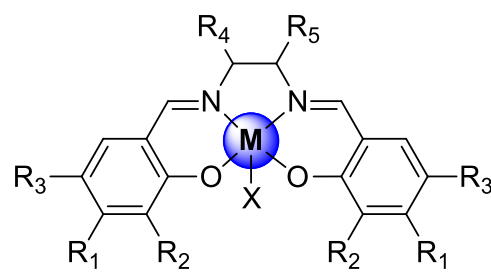

$\mathrm{M}=\mathrm{Al}, \mathrm{Cr}, \mathrm{Co}, \mathrm{Sn}$ $\mathrm{X}$ typically halide
BINAPHTHYL SALENS

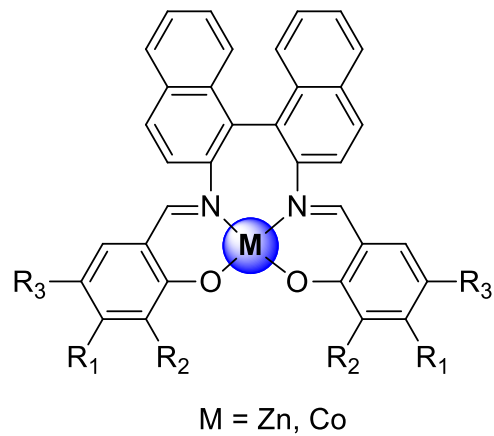

CYCLOHEXYL SALENS
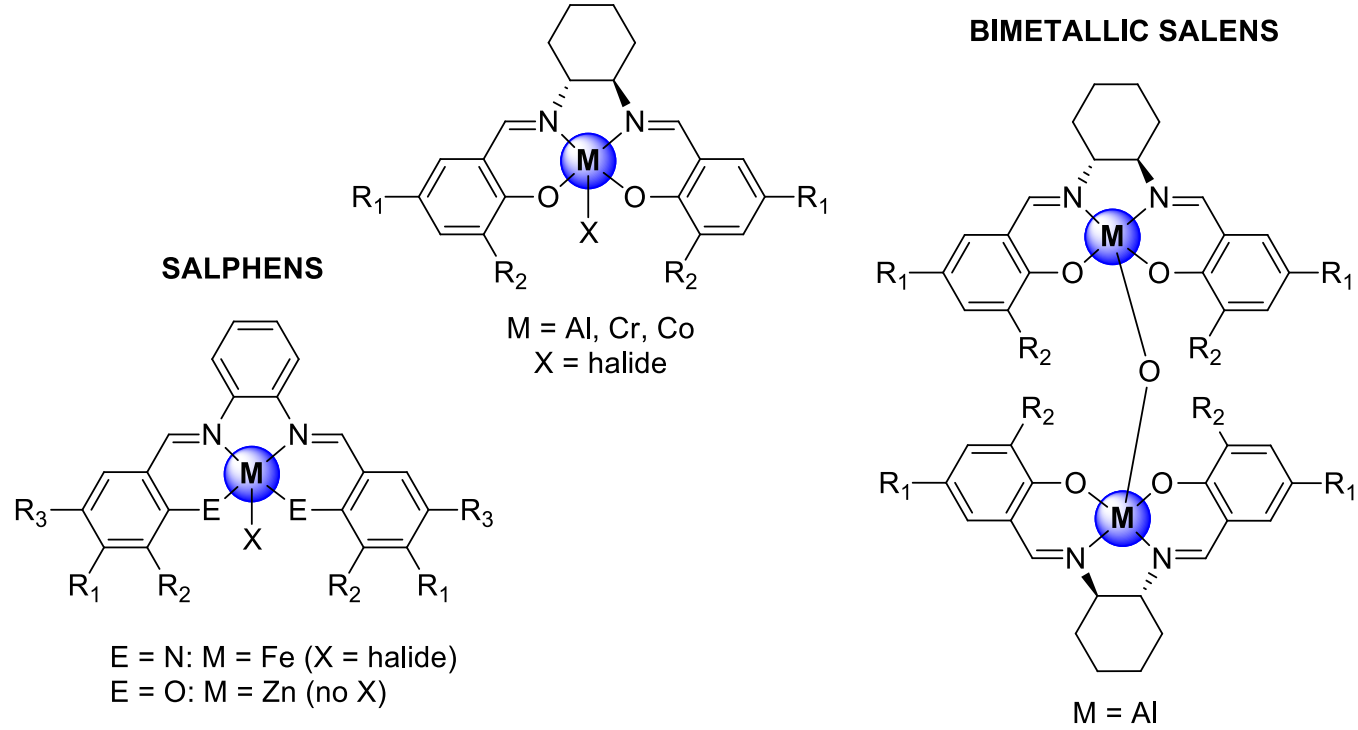

Figure 3. Most commonly used metal-salen structures derived from salen, salphen and binaphtyl-based ligand scaffolds.

A clear example that illustrates the easy fine-tuning of salen complexes with respect to chemo-selctivity was provided by the work from Darensbourg and co-workers. ${ }^{[8]}$ The presence of electron-donating or withdrawing groups on the backbone of the metal-salen complex can be used to favor the preferred formation of the cyclic or polycarbonate product. $^{[42-45]}$

Although there are various contributions that focus on the conversion of terminal epoxides into their respective carbonates in high yields and under relatively mild reaction conditions, ${ }^{[46-48]}$ further improvement of the substrate scope is still warranted. Both chemo-selectivity as well as higher reactivity are required to achieve high catalytic 
efficiency with less reactive substrates such as internal epoxides and oxetanes. As a potential solution for these challenges, other types of catalysts have to be considered. Kleij et $\mathrm{al}^{[33]}$ developed a binary catalytic system (Scheme 3 ) that consists of a triphenolate complex acting as Lewis acid and tetrabutylammonium bromide (TBAB) as co-catalyst. In this case, the choice of co-catalyst and also the ratio between the iron catalyst and the nucleophilic co-catalyst is of high importance as this controls the activity and selectivity ${ }^{[49]}$ of the reaction, allowing for instance the selective conversion of cyclohexene oxide into either the cyclic carbonate or the polycarbonate depending on the catalyst/nucleophile ratio.

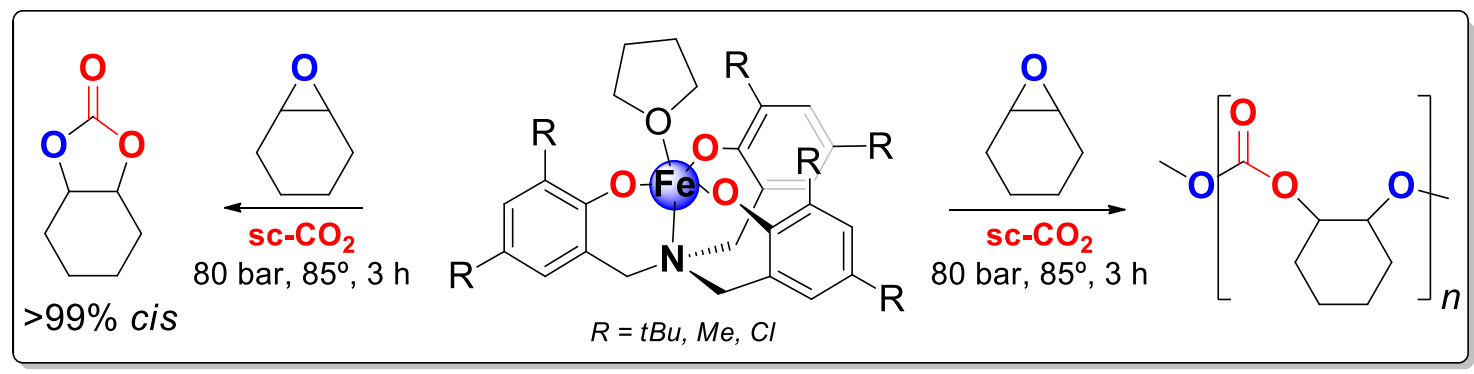

\section{Scheme 3. Reaction of cyclohexene oxide with carbon dioxide under supercritical conditions in presence of a binary catalyst system comprising of a Fe(III) aminotriphenolate complex.}

The stereo-controlled preparation of value-added commodities from $\mathrm{CO}_{2}$ has recently emerged as one of the future challenges. ${ }^{[50]}$ The use of optically active substances, in particular the ones which contribute to biological activity, are key substances in different areas such as the pharmaceutical industry and agriculture. Traditional extraction from natural sources cannot always satisfy the current demand for these type of compounds. This situation has resulted in the development of new alternative synthetic drugs that are obtained through asymmetric synthesis from racemic precursors. Taking advantage of the ease of modulation of salen ligands in general, groundbreaking approaches towards chiral epoxidation $^{[51,52]}$ and hydrolytic kinetic resolution of (rac)-epoxides ${ }^{[53]}$ have been developed by Jacobsen and Katsuki. These previous developments have been and still are of significant importance to the field of (poly)carbonate formation.

The simplest way to produce enantiopure cyclic carbonates is from enantiopure epoxides and carbon dioxide using catalytic procedures that favor a high level of retention of configuration at the chiral carbon center of the oxirane unit. DiBenedetto and Aresta ${ }^{[54]}$ used $\mathrm{Nb}(\mathrm{IV})$ and $\mathrm{Nb}(\mathrm{V})$ complexes based on chelating diphosphine, pyrrolidine or oxazoline ligands to convert $(R)$ - or $(S)$-configured terminal epoxides, hereby achieving retentions higher than $98 \%$. Kinetic resolution of racemic oxiranes is more attractive in this respect as it creates new chiral centers from cheaper precursors. The most widely studied substrate has been propylene oxide and chiral catalysts have been used that are 
able to convert one of the epoxide enantiomers with a significantly higher rate providing thus a basis for epoxide resolution. Lu and co-workers reported on an elegant and efficient chiral Co(III)salen/quaternary ammonium halide binary type catalyst (Scheme 4) that allows the direct synthesis of optically active cyclic carbonates from racemic epoxides under mild and solvent-free conditions. This study demonstrated clearly the influence of the anion of the quaternary ammonium salt in the binary catalyst systems, as it directs the enantiomeric purity and reaction rate. ${ }^{[55]}$

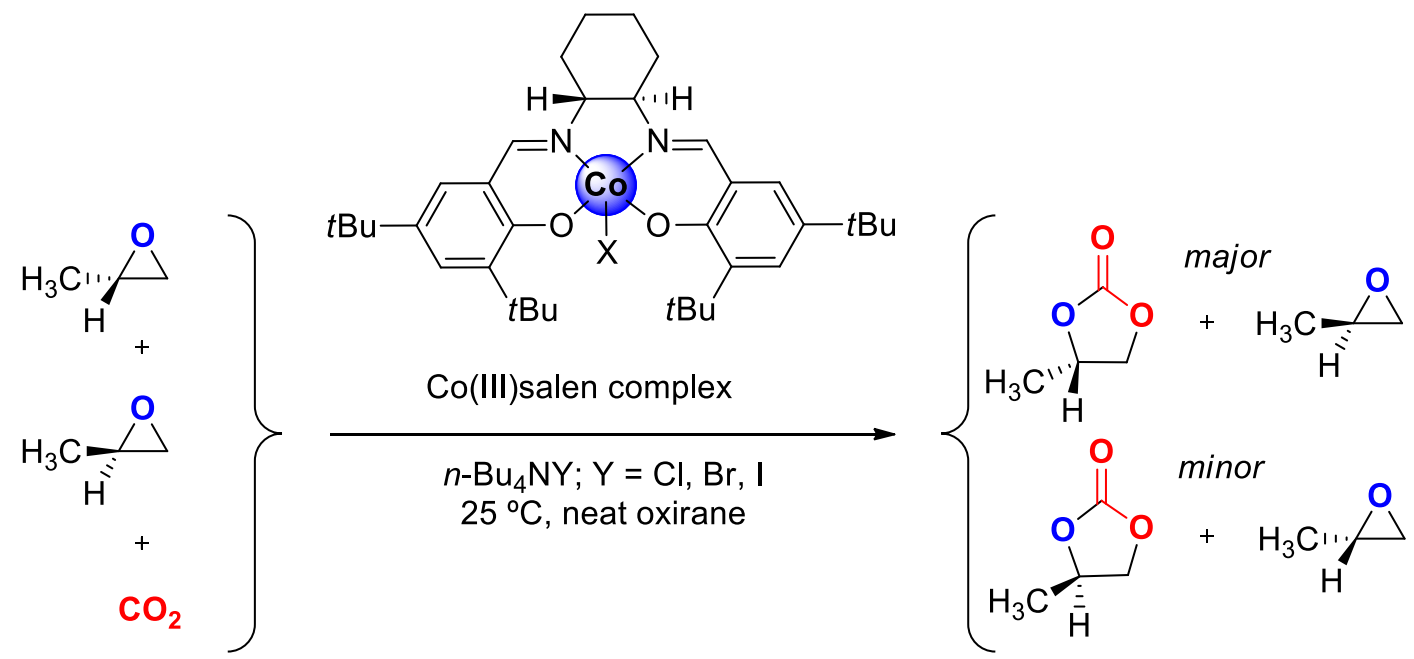

Scheme 4. Kinetic resolution of a racemic epoxide mixture using a Co(III)-salen type catalyst.
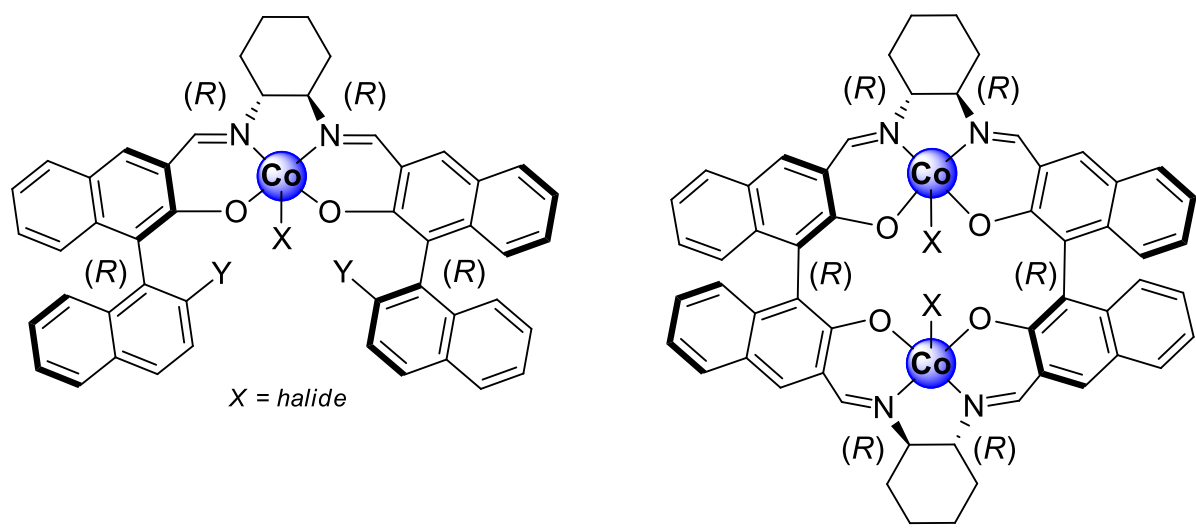

Figure 4. Example of BINAP-based Co(III)-salen structures used as chiral catalysts in $\mathrm{CO}_{2} /$ epoxide couplings. 
Other studies concerning the asymmetric coupling reaction between $\mathrm{CO}_{2}$ and oxiranes were carried out by Jing and co-workers, who developed chiral binaphthyl-based Co(III)salen complexes. In this case, the use of the binaphthyl-based salen ligands (see Figure 4) provided access to two different types of catalysts being either mono- or dinuclear. In both cases, the catalysts retained the chiral information in the bridging cyclohexyl fragment. ${ }^{[56]}$ The structural variety and success in catalytic operations is obviously an attractive feature, and for this reason it is not surprising that the vast majority of the catalysts developed for $\mathrm{CO}_{2}$ /epoxide couplings are based on $\mathrm{Co}$ (salen) structures.
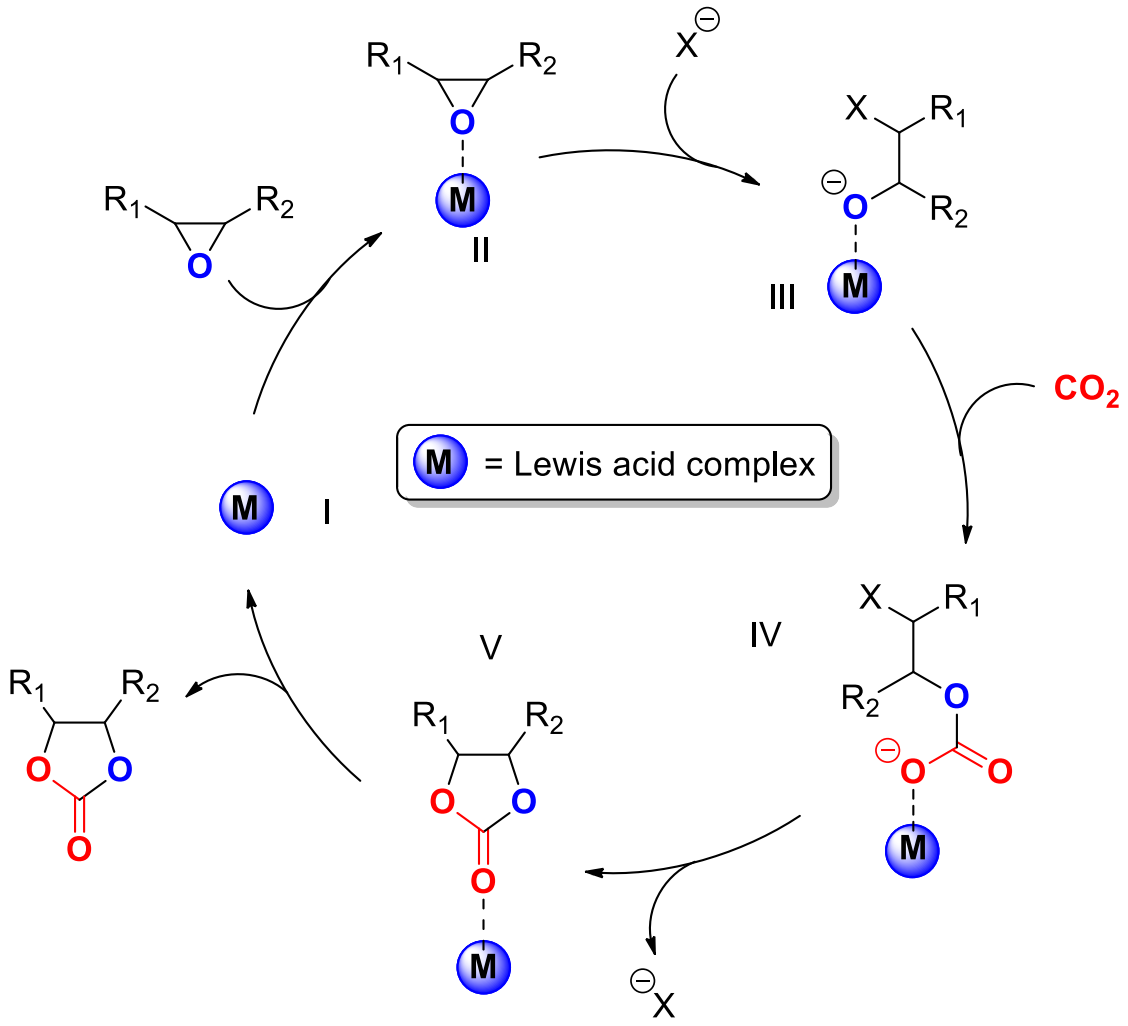

Scheme 5. Generally proposed mechanism for the coupling of $\mathrm{CO}_{2}$ to oxiranes and oxetanes catalyzed by a Lewis acid (M) in combination with a suitable nucleophile X.

Due to the ease of synthesis of these chiral M(salen) catalysts, other systems have also been studied including their Al(III) derivatives. The first studies reporting on this type of Al-catalyst focused on the polymerization of epoxides, ${ }^{[57]}$ but in 2002 , He et al. developed a binary catalyst system that mediated the formation of cyclic carbonate from propylene oxide in supercritical carbon dioxide in the presence of quaternary ammonium or phosphonium salts. ${ }^{[35,58]}$ A complementary study developed by $\mathrm{Lu}$ and co-workers showed how the coupling of $\mathrm{CO}_{2}$ and oxiranes is altered by changing the substitution on the aromatic rings of the salen ligands and by using various crown ethers as cocatalysts. ${ }^{[59]}$ North and co-workers demonstrated that bimetallic $\mathrm{Al}$ (salen) complexes display a much higher catalytic conversion than their monometallic analogues. In this case the reaction, which gave no conversion in the absence of either the catalyst or co- 
catalyst, took place under very mild conditions $\left(25^{\circ} \mathrm{C}, 1 \mathrm{~atm}\right)$, aspects that may be of interest for commercial applications. ${ }^{[60]}$

Other coordination/organometallic compounds such as $\left[\mathrm{M}\left(\mathrm{PR}_{3}\right) \mathrm{X}_{2}\right]\left(\mathrm{M}=\mathrm{Ni}^{[61]}, \mathrm{M}=\mathrm{Zn}\right)$, $\left[(\mathrm{dppp}) \mathrm{Mn}(\mathrm{CO})_{3} \mathrm{X}\right],{ }^{[37]}$ various copper complexes embedded in macrocyclic ligands, ${ }^{[62]}$ $\left[(\mathrm{OC}) \mathrm{CpRu}(\mu-\mathrm{dppm}) \mathrm{Mn}(\mathrm{CO})_{4}\right],{ }^{[63]}$ and $\left[\mathrm{VO}(\mathrm{acac})_{2}\right]^{[64]}$ are active in the synthesis of cyclic carbonates from $\mathrm{CO}_{2}$ and epoxides. However, when compared to the previously mentioned Co(salen) complexes, the scope, reactivity and/or selectivity features are generally less appealing.

The widely accepted mechanistic proposal that involves binary systems in the synthesis of organic carbonates is explained in Scheme 5. First, the oxirane/epoxide coordinates to the metal center through a coordinative $\mathrm{M}-\mathrm{O}$ bond (stage II) resulting in the activation of the epoxide. The anion $\mathrm{X}$ here acts as a nucleophile, usually attacking the less hindered side of the oxirane furnishing a metal-alkoxide intermediate species (III). Then, insertion of $\mathrm{CO}_{2}$ into the metal-alkoxide occurs to form a linear hemi-carbonate (IV) that undergoes a ring-closure leading to the formation of the cyclic carbonate $(\mathrm{V})$ that is released by the metal complex to allow for further turnover. Some of these elementary steps have been supported by X-ray crystallographic analysis (in the case of the resting state of some of the catalysts reported), ${ }^{[65]}$ and computational studies. ${ }^{[66]}$

\section{Bifunctional Catalysts}

In the last decades, the concept of green chemistry has turned out to be an important aspect in designing new catalytic systems. The use of less toxic or non-toxic metals, increase of energy efficiency and minimizing the amount of waste are key issues to be dealt with in synthetic chemistry. To address this problem, bifunctional catalysts have gained increased attention as they may offer more efficient strategies towards the conversion of organic substrates by means of cooperative and/or synergistic effects. ${ }^{[67]}$ Bifunctional catalysis in the context of $\mathrm{CO}_{2}$ conversion has also conquered a prominent position and the catalysts that are generally used differ from binary type catalysts having complementary built-in functions (i.e., basic sites or nucleophiles) that entropically favor catalytic turnover. Also, these bifunctional systems often allow for catalyst immobilization and do not require the presence of additional (external) co-catalytic additives thereby increasing the overall efficiency. Most known bifunctional catalysts have a counter-anion (= nucleophile) implemented in the catalytic structure in the form of an ammonium/phosphonium halide unit. The metal ion, counter-anion and substrate are all arranged in close proximity, which enhances the reaction rate and/or selectivity. Usually the co-catalyst unit used for ring-opening of the substrate (in the case of cyclic carbonate formation) is attached to the catalyst via a linker unit (L) and the rigidity as well as linker length are crucial for optimal catalyst performance. ${ }^{[68]}$

The proposed reaction mechanism for cyclic carbonate formation from $\mathrm{CO}_{2}$ /epoxide couplings mediated by bifunctional catalyst systems is rather similar to that reported for 
the binary systems (Scheme 5). Initial coordination of the epoxide to a metal complex is followed by ring-opening by intramolecular, nucleophilic attack from the anion. The anion is ion-paired to a (flexible) cationic linker group of the catalyst structure and therefore already in close proximity to facilitate the ring-opening step (Scheme). Subsequent steps proceed in a similar way as for the binary system, which finally leads to formation of the cyclic carbonate and regeneration of the catalyst.

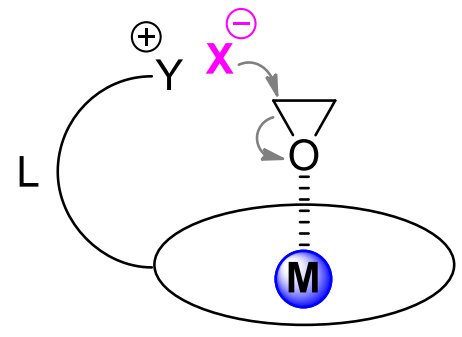

\section{Scheme 6. Conceptual approach towards cooperative activation of an epoxide by a bifunctional type catalyst. ${ }^{[69]}$}

An example of an effective bifunctional catalytic system was reported in 2009 by North et al. ${ }^{[70]}$ They reported on a bimetallic salen aluminium complex where the co-catalyst is implemented in the catalytic system by modifying the salen units with ammonium salts having bromide counter-anions. In terms of catalyst reactivity and stability the bifunctional catalyst gives similar or even better results than the binary system, ${ }^{[71]}$ leading to high yields under very mild conditions (atmospheric $\mathrm{CO}_{2}$ pressure, room temperature). The main advantage in comparison to the binary system is that this bifunctional catalyst can be immobilized on a solid support which opens the possibilities for use in flow reactors, and the same authors demonstrated at a later stage that this is indeed feasible. ${ }^{\text {[2] }}$ Although this bifunctional catalyst can be reused for multiple runs, the catalytic activity gradually decreases over the consecutive cycles probably due to retro-Mentshutkin or Hofmann elimination like chemistry. Similar strategies to create a bifunctional Alcatalyst having built-in quaternary ammonium salts led to a variety of one-component catalytic systems for cyclic carbonate formation. Whereas the first catalytic systems showed a considerable decrease in catalytic activity in subsequent cycles, the Al-salen catalyst reported by Darensbourg in 2012 showed higher stability towards moisture and heat, it tolerates process impurities and showing only a minor loss in activity over five catalytic cycles. ${ }^{[73]}$

Facilitating the immobilization of catalysts for flow reactors is not the only potential advantage of using a bifunctional catalyst. The selectivity for cyclic carbonate formation towards exclusive polymer formation in the coupling between an epoxide and $\mathrm{CO}_{2}$ can be achieved by replacing the binary system for a bifunctional analogue. This feature was demonstrated by Lu and coworkers using Co(salen) derived catalyst, and its binary and bifunctional derivative were evaluated in terms of chemo-selectivity behavior in the asymmetric copolymerization of $\mathrm{CO}_{2}$ and epoxides. ${ }^{[74]}$ 
A similar comparison was done by Darensbourg et al. employing bifunctional $(R, R)$ (salen) $\mathrm{M}$ (III) catalysts with $\mathrm{M}$ being $\mathrm{Cr}$ or $\mathrm{Co}{ }^{[75]} \mathrm{In}$ the latter case, the performance of a binary and a bifunctional catalyst were compared in the copolymerization of $\mathrm{CO}_{2}$ with either cyclopentene (CPO) or cyclohexene oxide (CHO). The binary catalyst system gives an excellent selectivity for polycarbonate formation when $\mathrm{CHO}$ is used as substrate, while in the case of CPO only cyclic carbonate is observed. The bifunctional catalyst (see Scheme 7), however, is able to form selectively the polycarbonate product from CPO with virtual perfect selectivity. The specific conformation of the bifunctional catalyts system promotes polymer chain growth instead of ring-closure that leads to cyclic carbonate formation.

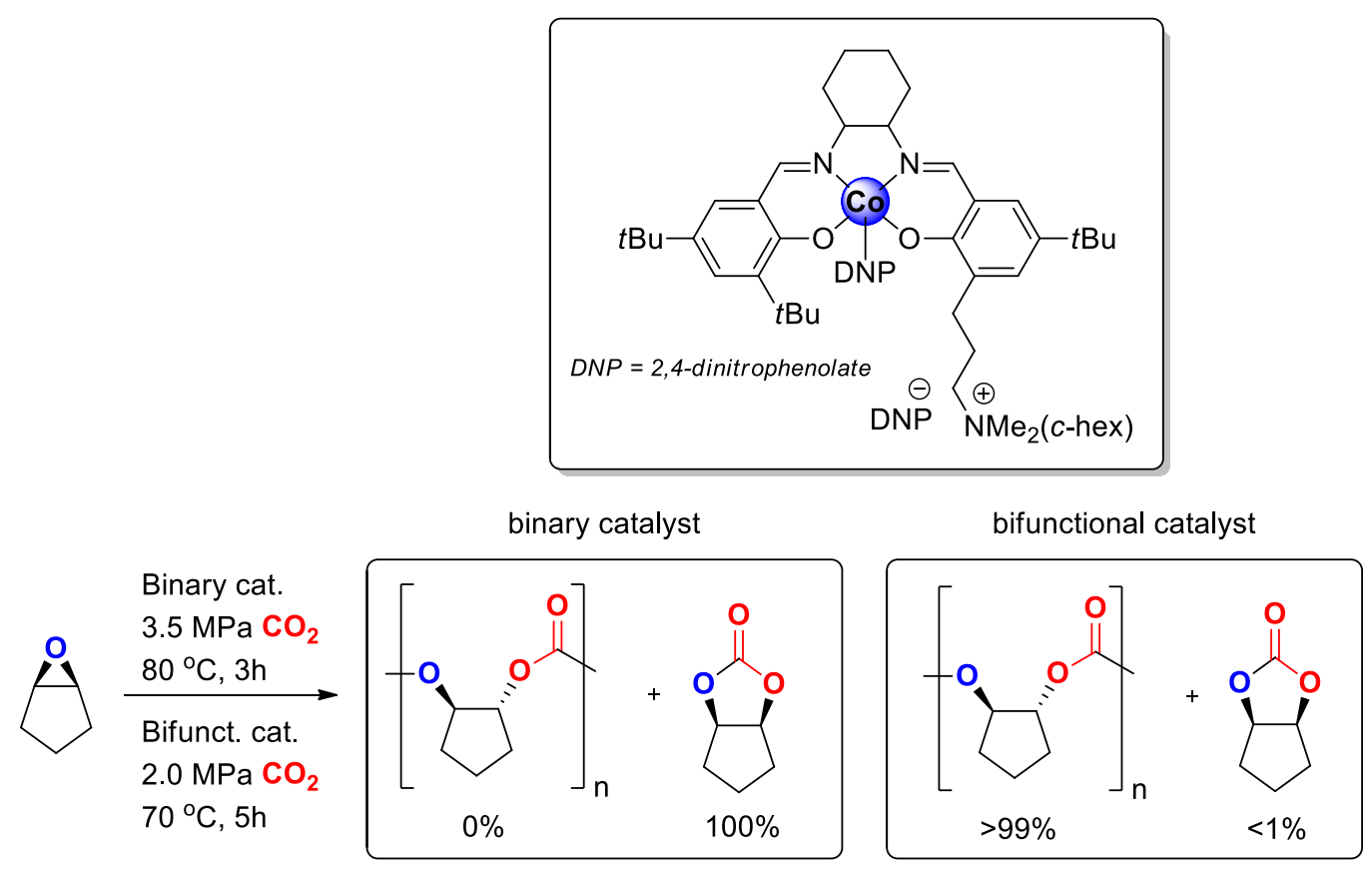

\section{Scheme 7. Improved selectivity towards polycarbonate formation from $\mathrm{CPO} / \mathrm{CO} 2$ using a bifunctional Co(salen) catalyst.}

Another interesting catalytic system was developed by Sakai and Ema, a bifunctional porphyrin-based catalyst modified with peripheral quaternary ammonium bromide groups (Scheme 8). ${ }^{[69]}$ This system exhibited an extremely high activity in the reaction of $\mathrm{CO}_{2}$ with epoxides, leading to one of the highest reported turnover numbers (TON's: 103 000) and turnover frequencies (TOF's: $12000 \mathrm{~h}^{-1}$ ). The cooperative effect of catalyst and co-catalyst induced by the bifunctional catalyst turned out to be highly important, as a binary type system comprising of a $\mathrm{Mg}$ (porphyrin) and tetrabutylammonium bromide (TBAB) gave only 4\% yield (TON: 5000) under similar conditions. Differently substituted epoxides could be converted with high yield (81-99\%) with no observable byproduct formation. 

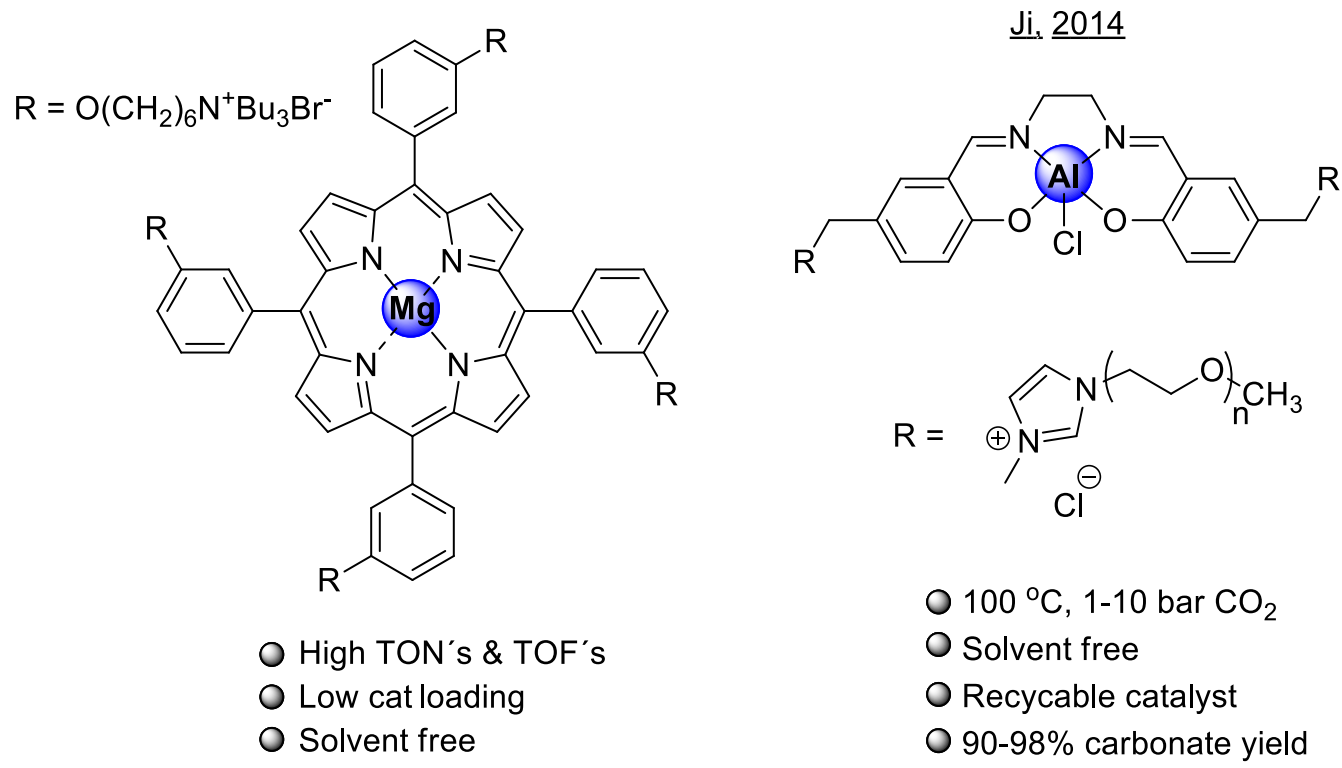

Scheme 8. Examples of successful bifunctional catalyst designs in cyclic carbonate formation.

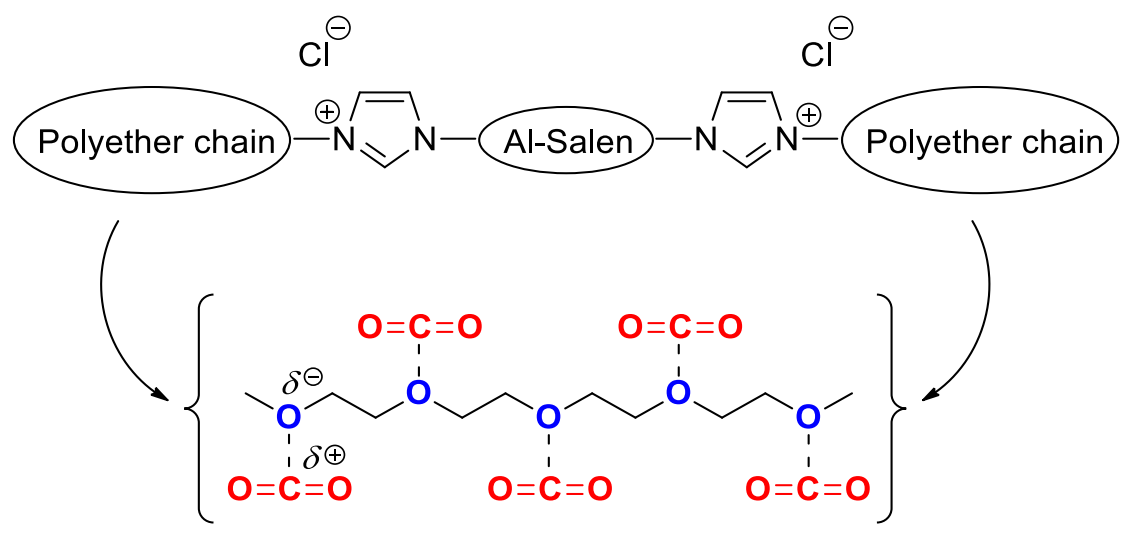

Scheme 9. Proposed " $\mathrm{CO}_{2}$ capture effect" by polyether chains. 
$\mathrm{Ji}$ and coworkers recently reported on an $\mathrm{Al}(\mathrm{III})$-salen complex functionalized by imidazolium groups (Scheme 8). ${ }^{[76]}$ These bifunctional Al(salen) complexes do catalyze the formation of cyclic carbonates from epoxides although in moderate yield. A significant enhancement in the yield of the carbonate product was obtained upon employing a trifunctional catalyst system having additional polyether chains incorporated. These polyether chains are proposed to increase the local density of $\mathrm{CO}_{2}$ by assumed weak interactions between the oxygen atoms of the ether fragments and $\mathrm{CO}_{2}$ as depicted in Scheme 9. As such, the reaction shows a significantly reduced diffusiondependent kinetic behavior and thus increased reactivity and product yields.

Various epoxides were converted in excellent yields (94-99\%) by the trifunctional catalyst. In comparison, the catalyst without polyether groups only provides moderate conversion or no reaction at all under similar conditions. Comparable effects of increasing the local concentration of $\mathrm{CO}_{2}$ by a judicious choice of the solvent medium have also been reported. ${ }^{[47]}$ Another advantage of these modified Al(salen) complexes is the facile catalyst separation and recyclability. The catalyst can be separated from the reaction mixture by addition of ether which causes the $\mathrm{Al}$ (complex) to precipitate. The catalyst can be used in subsequent catalytic cycles with virtually no loss in reaction rate and only a minor decrease in selectivity to $98 \%$ after 6 consecutive runs. Since the advent of bifunctional catalysis as an alternative to binary catalysis, various research groups have reported bifunctional catalysts of which the noteworthy ones include a bimetallic macrocyclic Fe(III) complex, ${ }^{[77]}$ a trinuclear bis-salphen metalloligand ${ }^{[78]}$ and other chiral Co(salen) based systems. ${ }^{[79]}$

\section{Addition of Carbon Dioxide to Double and Triple Bonds}

Chemical fixation processes with $\mathrm{CO}_{2}$ should preferably rely on low energy processes to minimize the net output of $\mathrm{CO}_{2}$ during the reaction. Ideally cyclic carbonates could be obtained from a reaction between $\mathrm{CO}_{2}$ and an unsaturated alcohol, leading to the formation of an elusive carbonic acid mono-alkyl ester, though these compounds are too unstable to be observed and isolated. ${ }^{[80]}$ An interesting strategy to overcome this problem was reported by Minakata et al. in 2010. ${ }^{[81]}$ They reported on the formation of carbonic acid intermediates from unsaturated alcohols and $\mathrm{CO}_{2}$. Despite the unfavorable thermodynamic equilibrium, the carbonic acid derivative can be conveniently trapped by tert-butyl hypoiodite $(t$-BuOI) to form a carbonic acid iodide intermediate (Scheme 10). In the presence of an alkene/alkyne, fast ring-closure towards a cyclic carbonate product is observed that drives the equilibrium towards the targeted product through an intramolecular addition onto the double bond. A variety of unsaturated alcohols with either alkene or alkyne accepting groups can be easily converted by this innovative reaction with good to excellent yields under very mild conditions using only 1 bar of $\mathrm{CO}_{2}$ at temperatures as low as $-20^{\circ} \mathrm{C}$. 


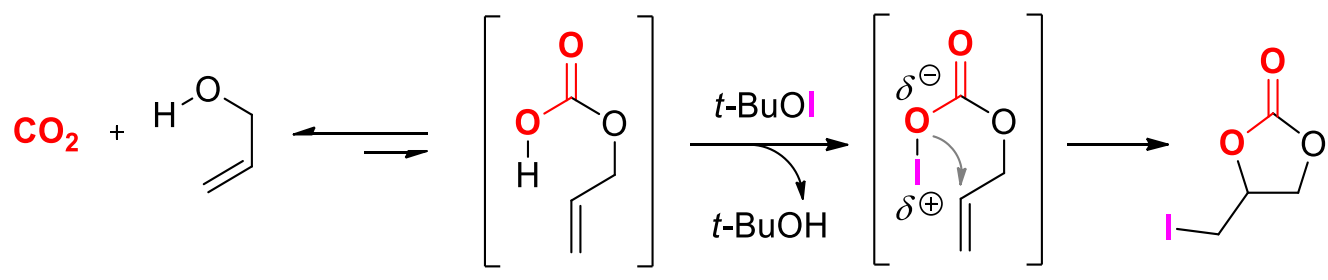

Scheme 10. Trapping of a carbonic acid intermediate with tert-butyl hypoiodite.

Another recent example of $\mathrm{CO}_{2}$ addition to unsaturated carbon-carbon bonds is the conversion of $\mathrm{CO}_{2}$ and olefins to form cyclic carbonates, a process reported by Hatton and Jameson in 2014. ${ }^{[82]}$ They used a flow system containing a combination of N-bromosuccinimide (NBS), 1,8-diazabicycloundec-7-ene (DBU) as a base, water and $\mathrm{CO}_{2}$. The optimal temperature for this reaction turned out to be $100^{\circ} \mathrm{C}$, as at lower temperatures the main product is the epoxide; at higher reaction temperatures the formation of the diol (through carbonate hydrolysis) is favored. Under these optimized reaction conditions, styrene could be fully converted into styrene carbonate in up to $85 \%$ isolated yield without the formation of byproducts.

The proposed mechanism ${ }^{[83]}$ of this reaction most likely follows one of the two pathways described in Scheme 11 using sodium bicarbonate as the $\mathrm{CO}_{2}$ source. The first step is the reaction of the olefin with NBS and water to form a reactive bromohydrin, which can be deprotonated by sodium bicarbonate to release $\mathrm{CO}_{2}$ and water. The anionic intermediate of the halohydrin can then react directly with $\mathrm{CO}_{2}$ to produce the cyclic carbonate (path A) or via the epoxide (path B). As the reaction that forms the epoxide proceeds faster than the coupling with $\mathrm{CO}_{2}$, a substantial amount of cyclic carbonate is supposed to form through the latter pathway. Although the approaches from Minakata et al. and Jamison/Hatton do not make use of metal catalysis, they serve as inspiring examples of efficient $\mathrm{CO}_{2}$ conversion catalysis examples.

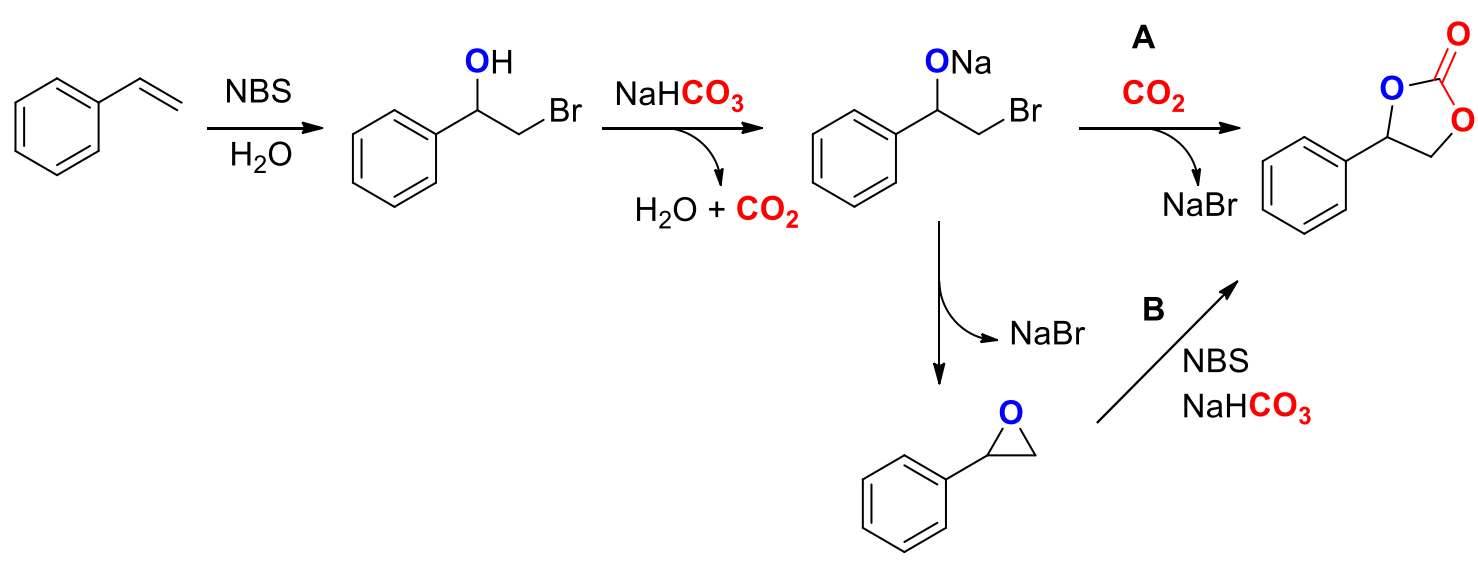

Scheme 11. Proposed mechanism for the formation of cyclic carbonates from olefins using a NBS/NaHCO3/water medium. 
Compared to carbon-carbon double bonds, the carbon-carbon triple bond is more reactive and thus generally does not require elevated temperatures for its reaction with carbon dioxide. The addition of a strong base or in some cases an organo-catalyst is sufficient to convert propargyl alcohols ${ }^{[84]}$ and propargyl amines ${ }^{[85]}$ to cyclic carbonates and oxazolidinones $^{[86,87]}$ respectively. Although there are various reported examples that concern the use of bases, this work will focus on metal catalyzed addition reactions that involve $\mathrm{CO}_{2}$ as a reagent. Significant contribution to this field was made by Yamada and coworkers, they reported on the Ag-catalyzed $\mathrm{CO}_{2}$ incorporation into propargylic alcohols. ${ }^{[84]}$ The $\mathrm{CO}_{2}$ reacts with the alcohol group of the substrate, after which ringclosure occurs through activation of the alkyne group by the Ag complex to give a cyclic carbonate with an exocyclic double bond. In subsequent work the same authors showed that cyclic carbonates can be formed from bis-propargylic alcohols at low temperatures allowing for practical enantio-selective reactions (Scheme 12). ${ }^{[88]}$ The combination of $\mathrm{AgOAc}$ and a chiral Schiff base ligand gave access to a variety of cyclic carbonates in high yields (90-98\%) and with $e e^{\prime}$ s of up to $93 \%$. These reactions can be performed under mild conditions using 10 bars of $\mathrm{CO}_{2}$ at $5^{\circ} \mathrm{C}$. At this temperature there is excellent enantiocontrol though at the expense of the reaction rate: under low-temperature conditions the reactions require 2-7 days to reach complete conversion of the substrates.
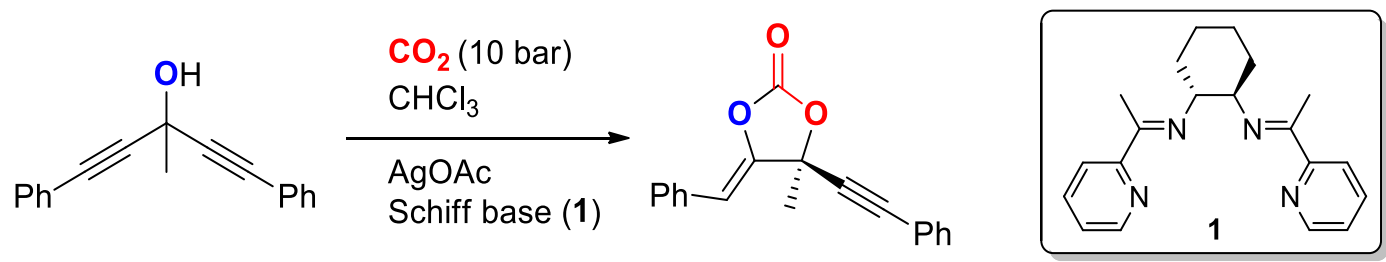

\section{Scheme 12. Addition of $\mathrm{CO}_{2}$ to a bis-propargylic alcohol catalyzed by a chiral silver complex based on Schiff base (1).}

An interesting contribution to this field was made by the group of Jiang that reported on $N$-heterocyclic carbene-Ag complexes immobilized on a polystyrene support. ${ }^{\left[{ }^{89]}\right.}$ Various terminal secondary and tertiary propargylic alcohols were conveniently converted to their cyclic carbonate products by this supported catalyst with excellent selectivity and yield. These reactions could be performed under relatively mild conditions at $40^{\circ} \mathrm{C}$ using 50 bars of $\mathrm{CO}_{2}$ pressure. For some of the more sterically hindered substrates, a slightly higher temperature was required to give high yields. An additional benefit of this system is its recyclability, after 15 catalytic cycles no significant change in the activity was observed. 


\section{Synthesis of Oxazolidinones Using $\mathrm{CO}_{2}$ and Metal Catalysts}

Oxazolidinones (also known as five-membered cyclic carbamates) are an important class of heterocyclic compounds widely present in pharmaceutically relevant organic structures. Particularly, 5-substituted oxazolidin-2-ones have shown extensive antibacterial and antimicrobial activity, and these structures are represented in several (commercially available) synthetic drugs (Figure 5). ${ }^{[90-93]}$ Furthermore these cyclic carbamates are frequently used in synthetic organic chemistry ${ }^{[50,94]}$ since Evans ${ }^{[55]}$ reported in 1981 on the use of enantiomerically pure 4-substituted oxazolidinones as chiral auxiliaries in asymmetric synthesis (i.e. the use of a polymer-supported chiral Evan's auxiliary in diastereoselective syn-aldol reactions). ${ }^{[96]}$ Finally, the commercialization of Linezolid, an oxazolidinone-based antibacterial drug raised the interest of the scientific community towards developing new synthetic routes for oxazolidinones especially those that are based on the use of $\mathrm{CO}_{2}$ as a reagent. ${ }^{[07]}$

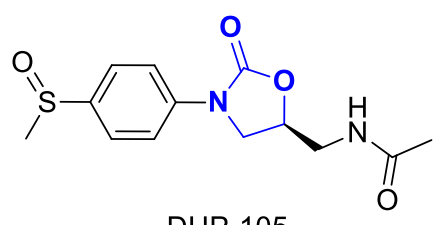

DUP-105

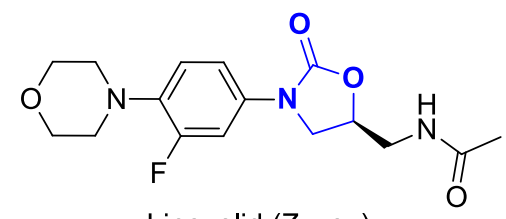

Linezolid (Zyvox)

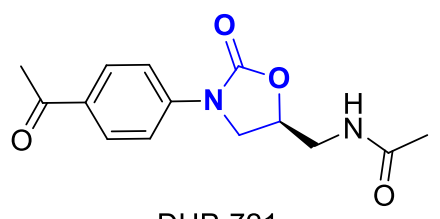

DUP-721

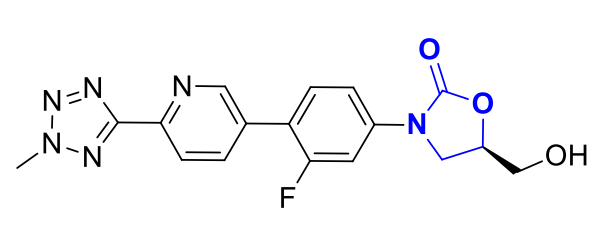

Torezolid

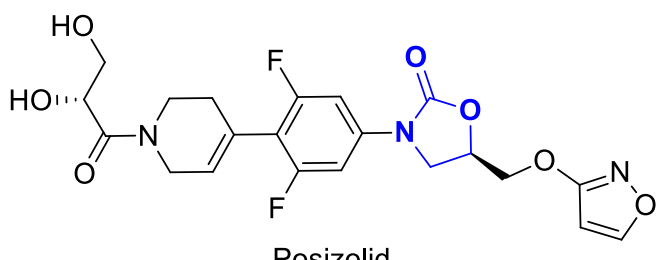

Posizolid

\section{Figure 5. Schematic structures of some oxazolidinone-based biologically relevant compounds. All are industrially produced as antibiotic against Gram-positive bacteria.}

The conventional preparation of oxazolidinones includes the use of environmentally harmful/toxic reagents such as phosgene, isocyanates or carbon monoxide. Most popular routes which lead to oxazolidinones include the carboxylation of 1,2-aminoalcohols using phosgene ${ }^{[98]}$ as a carbonyl source, coupling between epoxides and isocyanates ${ }^{[99]}$ or a two-step process involving the carboxylation of $\beta$-aminoalcohols with $\mathrm{CO}$ followed by an oxidative cyclization with molecular oxygen. ${ }^{[100]}$ As the oxazolidinone building block has gained extensive synthetic and medical applications over the last years, the development of greener chemical methodologies has attracted considerable attention. In order to avoid the use of phosgene or isocyanates, great effort has been devoted to incorporate $\mathrm{CO}_{2}$ as an alternative $\mathrm{C} 1$ carbon source. ${ }^{[101]}$ There are three main synthetic 
strategies using $\mathrm{CO}_{2}$ as $\mathrm{C} 1$ building block depending on the starting material employed: (1) insertion/addition of $\mathrm{CO}_{2}$ (in)to an aziridine moiety, (2) reaction of 1,2-aminoalcohols with $\mathrm{CO}_{2}$, and (3) reaction of propargylic amines with $\mathrm{CO}_{2}$. These methods will be discusses in more detail in the sections below.

\subsection{Insertion of $\mathrm{CO}_{2}$ into an aziridine moiety.}

Aziridines are important three-membered, small-sized heterocyclic compounds. Structurally, they are analogous to epoxides with the nitrogen group replacing the oxygen. The chemistry of aziridines has been studied extensively over the last few decades and their applications have been greatly expanded. Since aziridines are highly ring-strained compounds, they are promising candidates to react with relatively inert $\mathrm{CO}_{2}$ without the need for extreme reaction conditions. The direct coupling reaction between $\mathrm{CO}_{2}$ and aziridines represents obviously an attractive route to oxazolidinones compared to the processes based on phosgene or $\mathrm{CO}$. An efficient aziridine/ $\mathrm{CO}_{2}$ coupling reaction is $100 \%$ atom-efficient, which is an important factor for sustainable development. As a result, different research groups have developed relatively green approaches towards the synthesis of oxazolidinones through catalytic and non-catalytic routes. The reaction of aziridines with $\mathrm{CO}_{2}$ usually affords two regio-isomeric structures: the 4- and 5-substituted isomer (Scheme 13). The ratio between these two isomers is mostly dependent on the aziridine substituents $\left(\mathrm{R}^{1}\right.$ and $\mathrm{R}^{2}$;

Table).

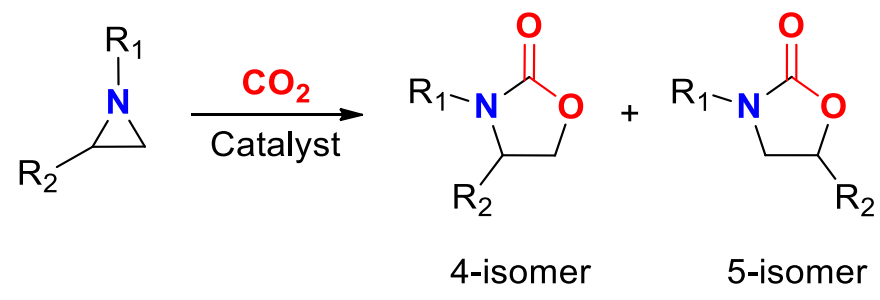

\section{Scheme 13. Reaction scheme of the insertion of carbon dioxide into an aziridine group.}

The main drawback in the synthesis of oxazolidinones from $\mathrm{CO}_{2}$ is the relative inertness of the latter combined with the lower reactivity of aziridines compared to epoxides. These limitations can be (partially) overcome by using a high $\mathrm{CO}_{2}$ pressure and/or electrolysis methods. ${ }^{[102]}$ Good results for the insertion of $\mathrm{CO}_{2}$ into the $\mathrm{C}-\mathrm{N}$ bond of aziridines have been obtained by electrosynthesis using stable and readily available complexes of $\mathrm{Ni}$ (II) incorporating a cyclam ligand (1, 4, 8, 11-tetra-azacyclo-tetradecane) or using a bipyridine ligand. The reaction takes place under extremely mild reaction conditions (ambient pressure and temperature) which provides a green chemical approach compared 
with existing methodologies. Both types of $\mathrm{Ni}$ (II) complexes led to the corresponding oxazolidinones in good yields (50-99\%) depending on the substituents present in the starting aziridine and displayed moderate to good regio-selectivities for the 4-isomer product $(50-84 \%)$.

Endo et al. reported in 2003 on the first selective synthesis of 2-oxazolidinones by coupling of $\mathrm{CO}_{2}$ with an aziridine. ${ }^{[103]}$ The conversion of 2-methylaziridine and 2phenylaziridine into their corresponding oxazolidinones was studied using simple and cheap metal halides as catalysts such as $\mathrm{LiBr}$ and $\mathrm{NaBr}$. In both cases, the reaction shows an excellent regio-selectivity and provides exclusively the 4-substituted oxazolidinone (Scheme 13). Whereas ambient conditions $\left(p \mathrm{CO}_{2}=1\right.$ bar and room temperature) were used for the coupling of 2-methylaziridine with $\mathrm{CO}_{2}$, an increase in the reaction temperature (up to $100^{\circ} \mathrm{C}$ ) was required for the conversion of 2-phenylaziridine probably as a result of an increasing steric effect at the ring-opening stage of the reaction.

Simultaneously, Pinhas and coworkers reported on the use of an identical metal halide catalyst for the conversion of $N$-substituted aziridines under similar conditions as those reported by Endo (i.e., ambient conditions). ${ }^{[104]}$ A dramatic effect of the aziridine substitution on the regio-isomer distribution was observed. When the $\mathrm{R}^{1}$ and $\mathrm{R}^{2}$ groups (

Table) groups are both alkyl groups, a 2:1 mixture of 4- and 5-isomer is obtained. On the other hand, if $\mathrm{R}^{2}$ is a phenyl group, the mixture product is almost quantitatively enriched in the 5-isomer. However, if $\mathrm{R}^{1}$ is a phenyl group (

Table) or any electron-withdrawing group, no reaction is observed at all.

\section{Table 1. Influence of the aziridine substituents on the oxazolidinone isomer ratio using different catalytic systems.}

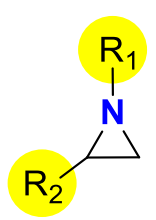

aziridine

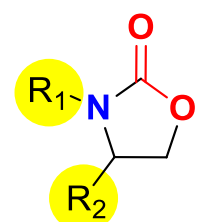

4-isomer

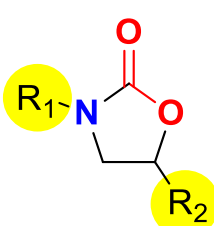

5-isomer

\begin{tabular}{ccccc}
\hline R 1 aziridine & $\mathrm{R}_{2}$ aziridine & $\mathrm{MX}_{\mathrm{n}}$ (Pinhas) & $\begin{array}{c}\text { Preferred oxazolidinone } \\
\mathrm{Co}(\text { salen)/DMAP } \\
(\text { Nguyen })\end{array}$ & $\begin{array}{c}\mathrm{ZrOCl}_{2} \cdot 8 \mathrm{H}_{2} \mathrm{O} \\
(\mathrm{Wu})\end{array}$ \\
\hline alkyl & alkyl & $67 \%(4)$ & 5-isomer & 4-isomer \\
alkyl & phenyl & 5-isomer & 5-isomer & 5-isomer \\
phenyl & phenyl & no reaction & 5-isomer & no reaction \\
\hline
\end{tabular}

This problem was solved by Nguyen in 2004, who reported on a highly active and selective catalyst ${ }^{[105]}$ based on a binary complex comprising of a $\mathrm{Cr}$ (III)-salen complex 
and 4-dimethylaminopyridine (DMAP) for the coupling reaction between $\mathrm{CO}_{2}$ and $\mathrm{N}$ substituted aziridines under mild reaction conditions. The Nguyen method proved to be successful with $N$-phenyl substituted aziridines (

Table; Scheme 14) which is highly important as all oxazolidinone-based biologically relevant compounds have $N$-aryl substitutions. In addition, for the first time this catalytic system showed a general and clear preference for the formation of the 5-isomer. The excellent regio-selectivity is of high importance as only the 5-substituted oxazolidinones have shown to exhibit biological activity. Furthermore, this binary complex shows high catalytic activity for a wide range of substrates and the oxazolidinone products were generally obtained in excellent yields and regio-selectivities.
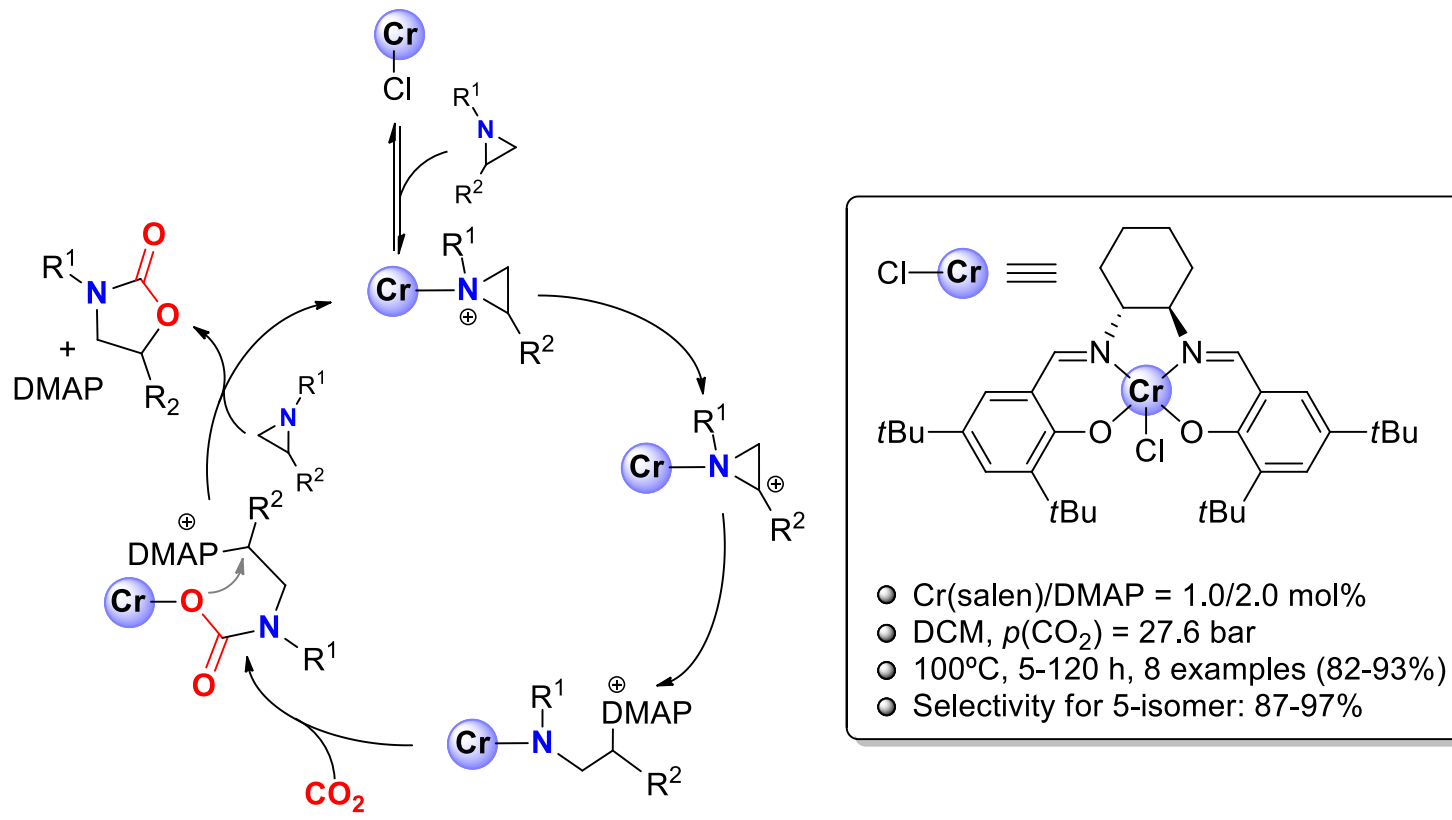

\section{Scheme 14. Proposed mechanism for the coupling of $\mathrm{CO}_{2}$ and aziridines by a Cr(III)-salen/DMAP binary catalyst system.}

The proposed mechanism is shown in Scheme 14. The aziridine is first activated by coordination to the metal center replacing the labile chloride atom. As a result of this coordinative interaction, a partially positive charge is delocalized over the aziridine ring allowing nucleophilic attack by the Lewis base co-catalyst DMAP at the most substituted carbon. The regio-selectivity of the reaction is controlled by this step affording predominantly the 5-isomer.

A different method to obtain 5-substituted oxazolidinones in excellent yields and regioselectivities was reported by $\mathrm{Wu}$ and coworkers. ${ }^{[106]}$ Zirconyl chloride $\left(\mathrm{ZrOCl}_{2} \cdot 8 \mathrm{H}_{2} \mathrm{O}\right)$ was used as an effective solid catalyst for the coupling between $\mathrm{CO}_{2}$ and aziridines under 
mild conditions without the need of any additives or solvent. This methodology was successfully applied to the synthesis of a variety of $\mathrm{N}$-alkyl-2-phenyl aziridines to obtain $\mathrm{N}$-alkyl-5-phenyl based oxazolidinones. The 4-substituted product is the predominant one when $\mathrm{CO}_{2}$ is coupled to 2-alkyl aziridines (

Table). The activity of the $\mathrm{ZrOCl}_{2} \cdot 8 \mathrm{H}_{2} \mathrm{O}$ catalyst, which is regarded to be an ionic cluster of $\left[\mathrm{Zr}_{4}(\mathrm{OH})_{8}\left(\mathrm{H}_{2} \mathrm{O}\right)_{16}\right] \mathrm{Cl}_{8}$, can be explained by the coexistence of Lewis acidic zirconium (IV) and Lewis basic chloride. The bifunctional catalyst can be easily recovered from the reaction mixture by filtration and reused for at least five times without significant loss in catalytic activity, rendering the process economically and potentially viable for commercial applications.

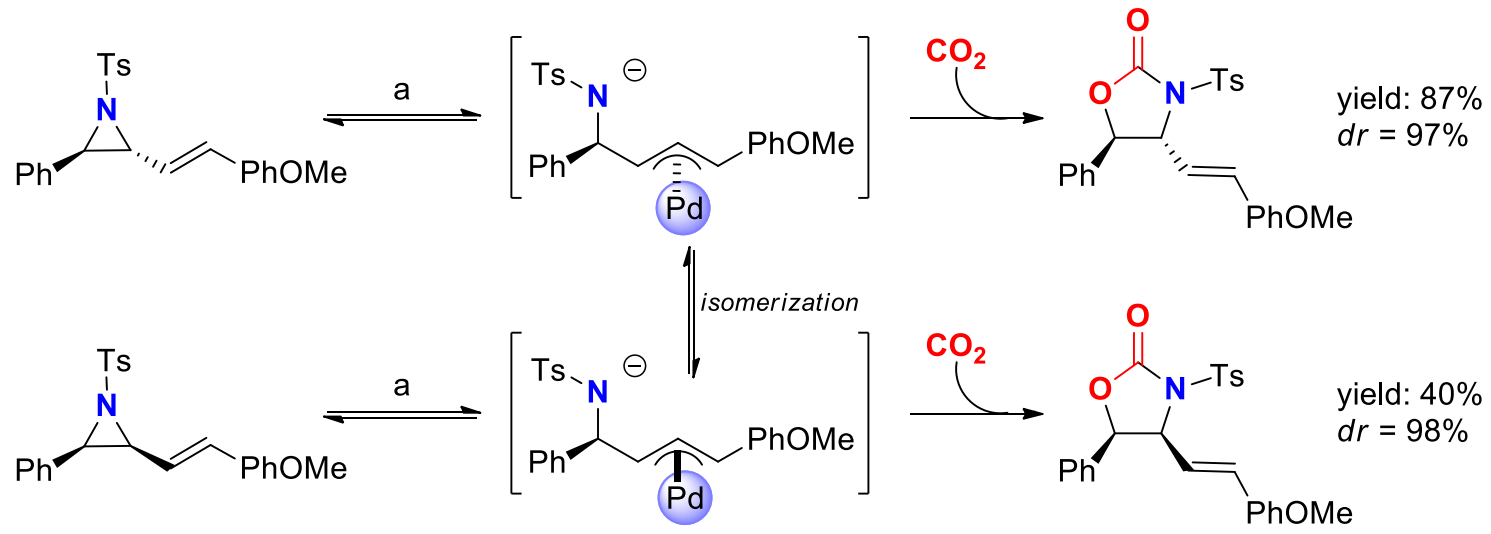

\section{Scheme 15. Stereo-selective palladium-catalyzed oxazolidinone synthesis from aziridines and $\mathrm{CO}_{2}$. (a) Reaction conditions: $\mathrm{Pd}_{2}\left(\mathrm{dba}_{3}, \mathrm{CHCl}_{3}, \mathrm{PPh}_{3}, \mathrm{TBAT}\right.$, $p\left(\mathrm{CO}_{2}\right)=1$ bar, toluene.}

In addition to these methods, other catalytic systems have been developed to get 4,5disubstituted oxazolidinones. Pinhas ${ }^{[104]}$ studied the formation and stereochemistry of oxazolidinones starting with 2,3-disubstituted aziridines. Using LiI as catalyst, high yields (85-90\%) were obtained for dialkyl substituted aziridines with retention of the starting cis/trans stereochemistry. At a later stage, a binary catalytic system composed of palladium-dibenzylideneacetone $\quad\left[\mathrm{Pd}_{2}(\mathrm{dba})_{3}\right]$ and tetrabutylammonium difluorotriphenylsilicate (TBAT) was reported by Aggarwal and coworkers ${ }^{[107]}$ to effectively convert 2-allyl-3-substituted aziridines to the corresponding oxazolidinones in mild conditions $\left(0^{\circ} \mathrm{C}\right.$ and 1 bar of $\left.\mathrm{CO}_{2}\right)$, see Scheme 15 . This Pd-mediated reaction proceeds with overall retention of configuration although the palladium intermediate can possibly isomerize to yield the product with opposite configuration. The effect of this isomerization process could almost be fully suppressed under the reaction conditions $\left(0^{\circ} \mathrm{C}\right)$ but becomes a significant competitive pathway at room temperature or in the absence of a halide salt. A $\operatorname{Pd}(0)$ complex acts as catalyst for the ring-opening "cyclization" reaction forming a $\pi$-allyl palladium intermediate. Trapping of this 
intermediate by $\mathrm{CO}_{2}$ gives the vinyloxazaolidinone after ring-closure by attack of the carbamate group onto the activated Pd-allyl fragment. 
Other methods for the coupling reaction between $\mathrm{CO}_{2}$ and aziridines comprise the use of $\mathrm{I}_{2},{ }^{[108,109]}$ organocatalysts such as $N$-heterocyclic carbenes ${ }^{[110]}$ or recyclable systems based on a polyethylene glycol support containing quaternary $\mathrm{NBu}_{3} \mathrm{Br}$ groups ${ }^{[111]}$ and polymersupported aminoacids. ${ }^{[20]}$ Interestingly, Pinhas et al. demonstrated that the coupling of aziridines and $\mathrm{CO}_{2}$ could also be performed without catalyst using 2-aryl- and 2alkylaziridines as substrates affording selectively the 5-oxazolidinones in good yields making use of high speed ball milling as a mechanical stimulus. ${ }^{[12]}$ However, this section focuses on metal-mediated processes thus these latter examples fall out of the primary scope of this chapter.

\section{$5.2 \mathrm{CO}_{2}$ coupling reactions with aminoalcohols and propargylic reagents}

Alternative ways to obtain oxazolidinones include the coupling of $\mathrm{CO}_{2}$ with 2aminoalcohols or propargylic amines (Scheme 16). However, these processes are not (always) atom-efficient, considerable harsh conditions may be required for efficient turnover and produce significant amounts of waste. Therefore, they are considered less sustainable than those based on aziridines and $\mathrm{CO}_{2}$ couplings and these methods will therefore only be briefly discussed in this chapter.

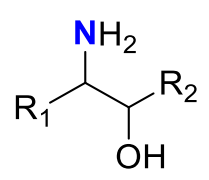

(a)

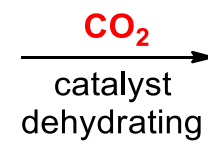
agent

(b)<smiles>[R]NCC#C</smiles>

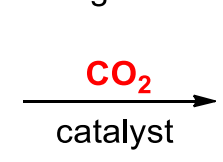<smiles>[R]N1CC(=C)OC1=O</smiles>

(c)<smiles>[R2]C1NC(=O)NC1[R7]</smiles>

Scheme 16. Synthesis of oxazolidinones from 1,2-amino alcohols (a) and $N$ substituted propargylamines (b). Under (c) an example of an imidazolidinone product observed by Shi et al.

Since 2-aminoalcohols are readily available derivatives of amino acids, they have been frequently used in the synthesis of oxazolidinones using $\mathrm{CO}_{2}$ as the carbonyl source. The main drawback of the reaction is finding a suitable dehydrating pathway after the insertion of $\mathrm{CO}_{2}$ in the 2-aminoalcohol moiety as the reaction is thermodynamically not favored. Nomura and coworkers reported the first organometallic catalyst for this reaction $\left(\mathrm{Ph}_{3} \mathrm{SbO}\right),{ }^{[13]}$ which was able to perform the conversion to 2-oxazolidinones in good yield (over $94 \%$ ) but under harsh temperature conditions $\left(160^{\circ} \mathrm{C}, 24 \mathrm{~h}\right)$ using molecular 
sieves $(3 \AA)$ as dehydrating additive. After this initial report, other catalysts were used in this transformation such as chlorostannoxanes reported by Ghosh. ${ }^{[14]}$ In the presence of 1,3-dichloro-1,1,3,3-tetraalkyldistannoxanes retention of chirality (up to 99\%) of the starting aminoalcohols and high turnover numbers (up to 138) were observed under the reaction conditions. Other catalytic systems that were studied for this reaction are based on the use of carbodiimides and phosphines. ${ }^{[115,116]}$

The reaction between propargylamines and carbon dioxide is one of the most common approaches towards the formation of unsaturated oxazolidinones. An important example of a binary catalyst system for the formation of these types of oxazolidinones was reported by Mitsudo ${ }^{[117]}$ in 1987 using a Ru catalyst [i.e., (4-1,5-cyclooctadiene) (6-1,3, 5cyclooctatriene)ruthenium) and a tertiary phosphine to give the 5-methylene-2oxazolidinone products from $\mathrm{N}$-substituted propargylamines and $\mathrm{CO}_{2}$ in high yield and good regio- and stereo-selectivity. In this context, Costa reported some interesting examples of unsaturated oxazolidinone formation in 1996 and 1999. First, the use of strong organic bases as catalysts for the synthesis of 5-substituted oxazolidinones was probed using propargylamines ${ }^{[86]}$ and hereafter oxazolidinone synthesis was investigated using $\mathrm{PdI}_{2}$ as catalyst. ${ }^{[18]}$ With this methodology, 3-substituted oxazolidinones were obtained in good yields and with a 1:3 E/Z ratio after optimization of the reaction conditions. Shi and coworkers also studied various palladium based catalysts such as $\mathrm{Pd}(\mathrm{OAc})_{2}$ and $\mathrm{Pd}\left(\mathrm{PPh}_{3}\right)_{4}$ for the reaction between propargylamines and $\mathrm{CO}_{2}$ under mild reaction $\left(20^{\circ} \mathrm{C}\right)$ conditions. ${ }^{[119]}$ The latter example demonstrates that the chemoselectivity can be an issue when propargylic amines are used as substrates. The combination of a suitable Pd salt in combination with an appropriate counteranion can drive the selectivity towards the desired oxazolidinone or alternatively towards the imidazolidinone product (Figure 9, c). The use of a basic phosphine $\left[\mathrm{P}(t \mathrm{Bu})_{3}\right]$ fully suppressed the formation of the imidazolidinone and gave the highest yield of the desired oxazolidinone $(90 \%)$.

\section{Synthesis of Ureas}

Ureas and their derivatives are important type of organic compounds where two amine groups are connected by a carbonyl group. They are important end-products or intermediates for pharmaceuticals, agricultural pesticides, antioxidants in gasoline, dyes, and resin precursors. ${ }^{[120]}$ Many cyclic derivatives can be synthesized using $\mathrm{CO}_{2}$ as a reactant. Substituted 2,4-dihydroxyquinazolines have been interesting for their biological activities. For example, 7-chloro-1-carboxymethyl-3-(4-bromo-20-fluorophenylmethyl)$2,4(1 H, 3 H)$ quinazolinone was developed as an aldol reductase inhibitor for a remedy of complications of diabetes mellitus. Quinazolinones are also a class of drugs which function as hypnotic/sedative drugs that contain a 4-quinazoline core (Figure 6). 
<smiles>O=C1CNCCN1</smiles>

cyclic urea scaffold<smiles>c1ccc2ncncc2c1</smiles>

quinazoline core<smiles>O=c1ncc2ccccc2[nH]1</smiles>

2-quinazolinone<smiles>O=c1[nH]cnc2ccccc12</smiles>

4-quinazolinone

Figure 6. Structures of some urea/urea-like scaffolds.

Generally, their synthesis is carried out by treatment of anthranilic acid with urea, anthranilamide with phosgene or carbon monoxide with sulfur, or anthranilic acid with potassium cyanate. Obviously, these methods are considerably limited because of the high toxicity of the reagents employed and/or the drastic reaction conditions applied. Mizuno et $\mathrm{al}^{[121]}$ reported in 2000 the first synthesis of these type of compounds using $\mathrm{CO}_{2}$ as a reactant. 2,4-Dihydroxyquinazolines were prepared in high yield starting from 2-aminobenzonitriles and $\mathrm{CO}_{2}$ under mild conditions $\left(1 \mathrm{~atm}, 20^{\circ} \mathrm{C}\right)$ in the presence of DBU. The use of DBU is disadvantageous due to problems associated with its handling including its hygroscopic nature, high viscosity, and tedious rework procedures. Following the need for simpler and more practical methods for the synthesis of these compounds, Bhanage et al. proposed ${ }^{[122]}$ an alternative method using cesium salts for the synthesis of quinazoline-2,4(1H,3H)-diones using $\mathrm{CO}_{2}$ and 2-aminobenzonitriles.

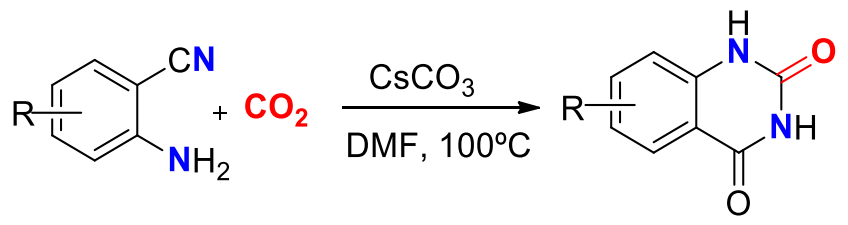

Scheme 17. Bhanage's dihydroxyquinazoline synthesis from 2-aminobenzonitriles.

The proposed mechanism starts with deprotonation of the Ar- $\mathrm{NH}_{2}$ that reacts with $\mathrm{CO}_{2}$ to afford a Cs-amide intermediate. This amide then attacks the nitrile group in an intramolecular process giving rise to a cyclized species that rearranges into an isocyanate intermediate followed by another intramolecular process where a hydroxyl-imine group attacks the carbon center of the isocyanate yielding a new cyclized compound that finally stabilized/rearranges into the desired dihydroxyquinazoline. Improvements of the method are still required as the process still needs high pressures ( $\geq 13$ bar) and temperatures $\left(100^{\circ} \mathrm{C}\right)$.

Other basic catalysts which have proved to be very efficient in $\mathrm{CO}_{2}$ fixation (TON up to 938) into urea derivatives are polyoxometalates such as the mononuclear and simplest tungstate $\left[\mathrm{WO}_{4}\right]^{-2} . \mathrm{TBA}_{2}\left[\mathrm{WO}_{4}\right]\left(\mathrm{TBA}=\left[\left(n-\mathrm{C}_{4} \mathrm{H}_{9}\right)_{4} \mathrm{~N}\right]^{+}\right)$, can act as a highly efficient homogeneous catalyst for the conversion of $\mathrm{CO}_{2}$ with amines, 2-aminobenzonitriles, and 
propargylic alcohols to give urea derivatives, quinazoline-2,4(1H,3H)-diones, and unsaturated cyclic carbonates, respectively. ${ }^{[123,124]}$ Interestingly, the tungstate used in this latter work seems to be able to activate both types of substrates, and NMR investigations have supported that the (bifunctional) catalyst species is involved in binding of a $\mathrm{CO}_{2}$ molecule thus activating it for catalytic turnover. Mechanistic investigation ${ }^{[124]}$ showed unambiguously that the formation of a carbamic acid intermediate and its subsequent conversion by $\mathrm{TBA}_{2}\left[\mathrm{WO}_{4}\right]$ plays a key role in synthesis of the heterocyclic products. Other methods towards quinazoline derivatives using $\mathrm{CO}_{2}$ as reagent have also recently been disclosed. ${ }^{[125]}$

\section{Formation of Lactones}

A lactone is defined as a cyclic ester and it may be regarded as the condensation product of an alcohol and an acid group within the same molecule. It consists of a cycle of at least 2 carbon atoms and a single endo-cyclic oxygen atom with an adjacent carbonyl group. In this section we will focus on the importance of this type of molecules and the different synthetic routes that have been reported utilizing $\mathrm{CO}_{2}$ as a key reagent. The kinetic stability of $\mathrm{CO}_{2}$ towards its conversion represents a huge challenge, and therefore the development of catalytic methods for its activation is crucial. Cyclic structures containing ester functions require complex synthetic routes, and their formation can be formally achieved through the insertion of $\mathrm{CO}_{2}$ into $\mathrm{C}-\mathrm{H}, \mathrm{C}-\mathrm{C}, \mathrm{E}-\mathrm{C}$ or $\mathrm{C}-\mathrm{O}-\mathrm{C}$ bonds $(\mathrm{E}$ represents other elements than $\mathrm{H}, \mathrm{C}$ or $\mathrm{O}$ ). These reactions are expected to have favorable thermodynamics associated to adverse kinetics. The main $\mathrm{CO}_{2}$ activation strategy has been the direct interaction of the $\mathrm{CO}_{2}$ molecule with a metal center. The first structurally characterized metal complex capable of binding $\mathrm{CO}_{2}$ was reported in 1975 by Aresta and coworkers ${ }^{[126]}$ and since then, the insertion of $\mathrm{CO}_{2}$ into $\mathrm{M}-\mathrm{E}$ bonds has been intensively investigated with the aim of discovering new catalysts for (direct) $\mathrm{CO}_{2}$ conversion.

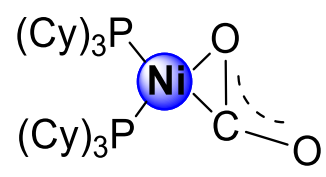

Figure 7. A $\eta^{2}-(\mathrm{C}, \mathrm{O})$ chelating $\mathrm{CO}_{2}$ complex reported by Aresta et al.

In essence, there are two principal routes considering $\mathrm{CO}_{2}$ insertion into organic molecules leading to lactone based structures: (1) reactions of $\mathrm{CO}_{2}$ with olefins or alkynes, and (2) the insertion of $\mathrm{CO}_{2}$ into metal-element bonds, which, depending on the co-reactants, leads to different transformation products such as carboxylates, esters, or carbonates. First, the focus will be on the first route which leads to the production of lactones and metallo-lactones. In nearly all reported cases, late transition metals have been used including $\mathrm{Fe}(0), \mathrm{Rh}(\mathrm{I}), \mathrm{Ni}(0), \mathrm{Pd}(0)$ and $\mathrm{Pd}(\mathrm{II})$ ) as they are highly basic and 
capable of binding weak $\sigma$-donor ligands such as olefins through $\pi$-back bonding. Many recent reports are still based on the initial research from the 1970s and 1980s, published by the groups of Inoue, Musco, Hoberg, Walther, and Behr, who focused their research in the field of catalytic $\mathrm{CO}_{2}$ activation. The pioneering examples of lactone formation using $\mathrm{CO}_{2}$ were provided by Inoue et al. and Musco et al. in the late $1970 .{ }^{[127-131]}$ Using $\mathrm{Pd}(\mathrm{dppe})_{2}$ as a catalyst, ${ }^{[130]}$ 1,3-dienes could be activated towards coupling with $\mathrm{CO}_{2}$ to afford five- and six-membered lactones (Scheme 15a) although resulting in a (complex) mixture of products. Another interesting contribution in the field of lactone formation reported on the coupling between $\mathrm{CO}_{2}$ and (substituted) methylenecyclopropanes ${ }^{[129]}$ using a $\mathrm{Pd}(0)$ complex based on $\mathrm{Pd}(\mathrm{dba})_{2}$ and $\mathrm{PPh}_{3}$ (ratio 1:4) as catalyst (Scheme 19b). The main issues of these reactions were the high $\mathrm{CO}_{2}$ pressures needed (40 bar) combined with low chemo-selectivity. Two types of lactones were observed, one with an exo-cyclic and one with an endo-cyclic double bond and a challenge is the combination of high conversion, high selectivity for either lactone while maintaining high isolated yields.

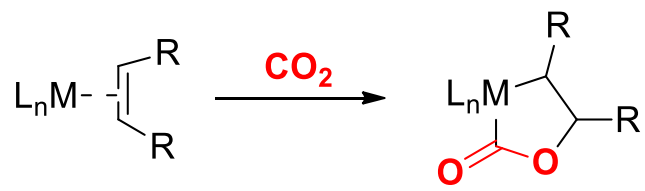<smiles>[R]C#C[R]</smiles>

Scheme 18: Reaction of $\mathrm{CO}_{2}$ with olefins and alkynes giving metallo-lactones.

(a)

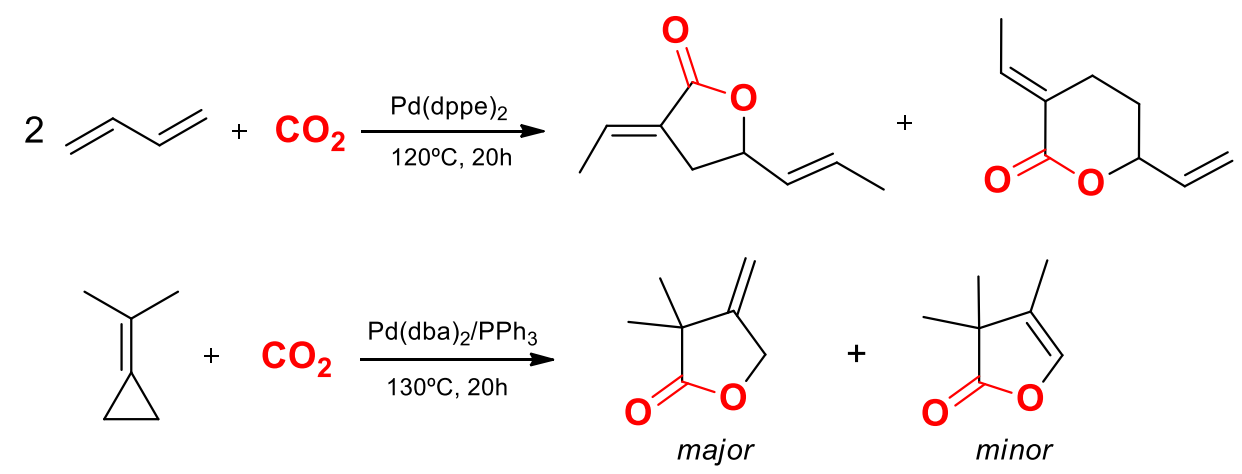

Scheme 19. Inoue's contributions in the field of lactone formation using $\mathrm{CO}_{2}$ : (a) dppe $=\operatorname{Ph}_{2} \mathbf{P}\left(\mathrm{CH}_{2}\right)_{2} \mathbf{P P h}_{2},(\mathrm{~b}) \mathbf{d b a}=$ dibenzilideneacetone . 
The reaction involving the telomerisation of butadiene with $\mathrm{CO}_{2}$ (Scheme 19a) to form a functional lactone has been a topic of intensive research after the first contributions from Inoue and coworkers as these lactones potentially have multiple applications as an organic intermediate. Over the years, the yields and selectivity have been successfully increased (up to $48 \%$ and $95 \%$, respectively) and the process was optimized to mini-plant scale. ${ }^{[132-}$ 134] Several investigations were conducted to explain in more detail the reaction/mechanistic pathway (Scheme 20).

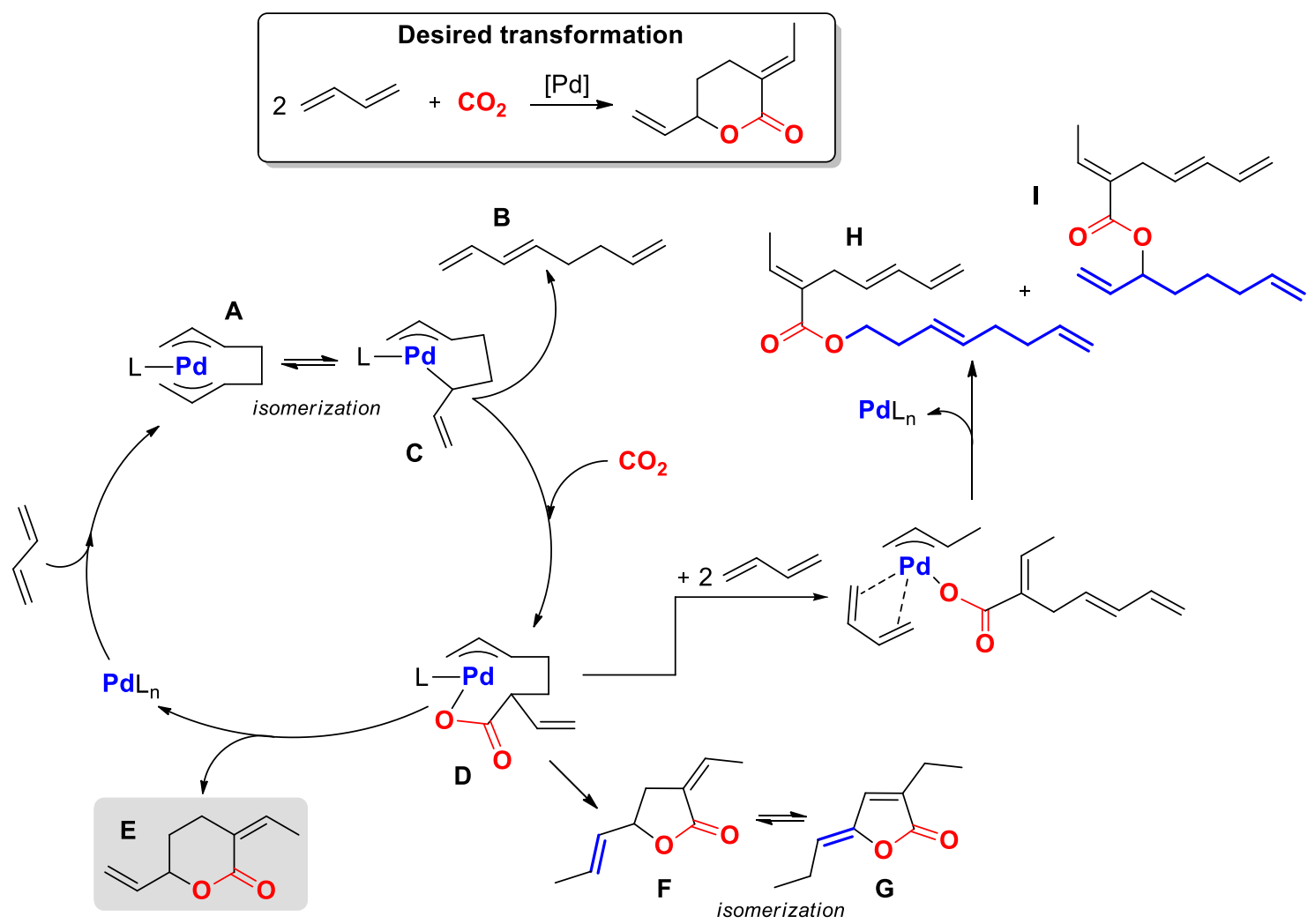

\section{Scheme 20. The reaction mechanism for the telomerization of $\mathrm{CO}_{2}$ and butadiene proposed by Behr et al.}

The proposed reaction mechanism involves the formation of a $\mathrm{Pd}(0)$ phosphine complex $\left(\mathrm{PdL}_{n}\right)$ from a palladium(II) precursor and a tertiary phosphine. The second step is the coordination of two butadiene molecules forming a bis- $\eta^{3}$-allyl Pd-complex $\mathbf{A}$. This species is in equilibrium, and can either react to form 1,3,7-octatriene $\mathbf{B}$ or give rise to an allylic carbonate $\mathbf{D}$ by insertion of $\mathrm{CO}_{2}$ in one of the allylic-Pd bonds in $\mathbf{C}$. Through ringclosure of this intermediate $\mathbf{D}$ various cyclic lactones can be obtained, although there are side reactions which can produce other, aliphatic cyclic esters $\mathbf{F}$ and $\mathbf{G}$. Another important side reaction that has to be taken into account is that the Pd catalyst can also promote the coupling of a different number of molecules of butadiene before the carboxylation step, 
which leads to linear open-chain ester products of different length/size (cf., formation of $\mathbf{H}$ and I). This complex mechanism therefore explains the low yield and poor selectivity of the reaction the first seminal reports, but clearly optimization based on byproduct recycling drastically increased the selectivity towards the $\delta$-lactone $\mathbf{E}$.

The resulting lactone is highly functional allowing for various post-synthetic manipulations. Through further conversion with different bulk reagents several relevant industrial products may be prepared and the lactone could be regarded as an ideal chemical platform molecule amenable towards hydrogenation, hydroformylation, hydroamination, oxidation, polymerization among other valuable conversions (Scheme 21).

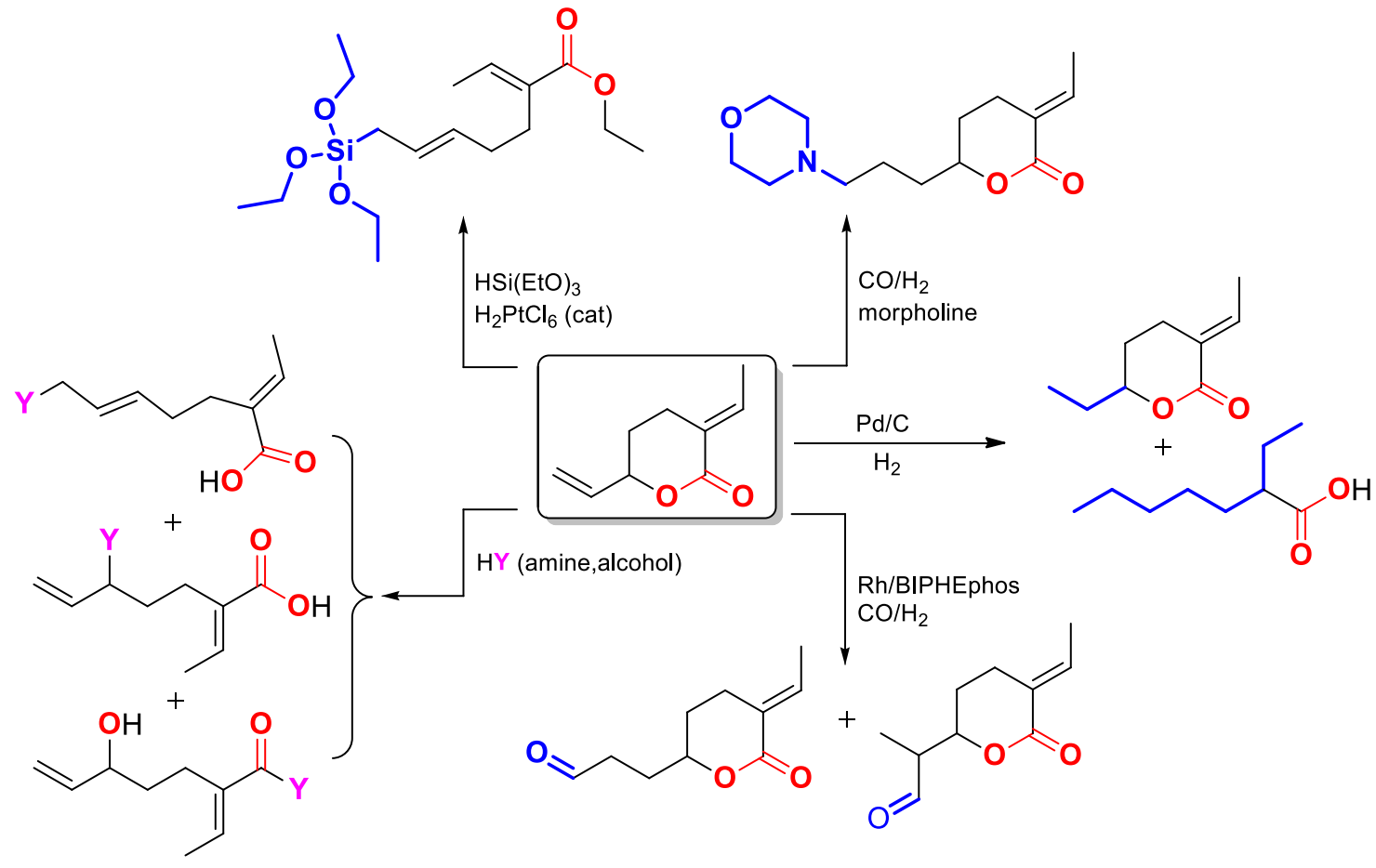

Scheme 21. Functionalization reactions of the $\delta$-lactone $\mathbf{E}$ from Scheme 20 towards several products with potential industrial applications.

In 2014 Nozaki $^{[135]}$ and coworkers were able to develop a strategy to create a polymer from dienes and $\mathrm{CO}_{2}$ in which $\mathrm{CO}_{2}$ represented $29 \%$ of the weight of the product. The key feature to make this process feasible was to employ the meta-stable $\delta$-lactone $\mathbf{E}$ to overcome the thermodynamic barrier. Copolymerization of $\mathrm{CO}_{2}$ and dienes to form polylactones has always been an appealing research topic as it would allow for the preparation of new materials from inexpensive feed stocks such as $\mathrm{CO}_{2}$ and dienes. This has generally not been possible due to the inertness of $\mathrm{CO}_{2}$ combined with the high kinetic barrier associated with the alternating copolymerization of ethylene/polyene and $\mathrm{CO}_{2}$. 
Nozaki et al. made clever use of the optimized synthetic methodology developed by Behr for $\delta$-lactone $\mathbf{E}$ which could easily undergo thermally initiated radical polymerization under aerobic conditions in the presence of an appropriate thermally activated radical initiator [i.e., $\mathrm{ABCN}=1,1$ '-azo-bis(cyclohexane-1-carbonitrile)]. The system was optimized to obtain high molecular weights $(62-85 \mathrm{kDa})$ with narrow molecular weight distributions (PDI's around 1.3) and polymer yields around 48\%. As depicted in Scheme 22 , the copolymerization results in the formation of several isomeric subunits in the polymer. The scope of polymerization reactions was extended to the incorporation of more complex diene structures (e.g., 1,3-pentadiene and isoprene) within the polymeric chain.
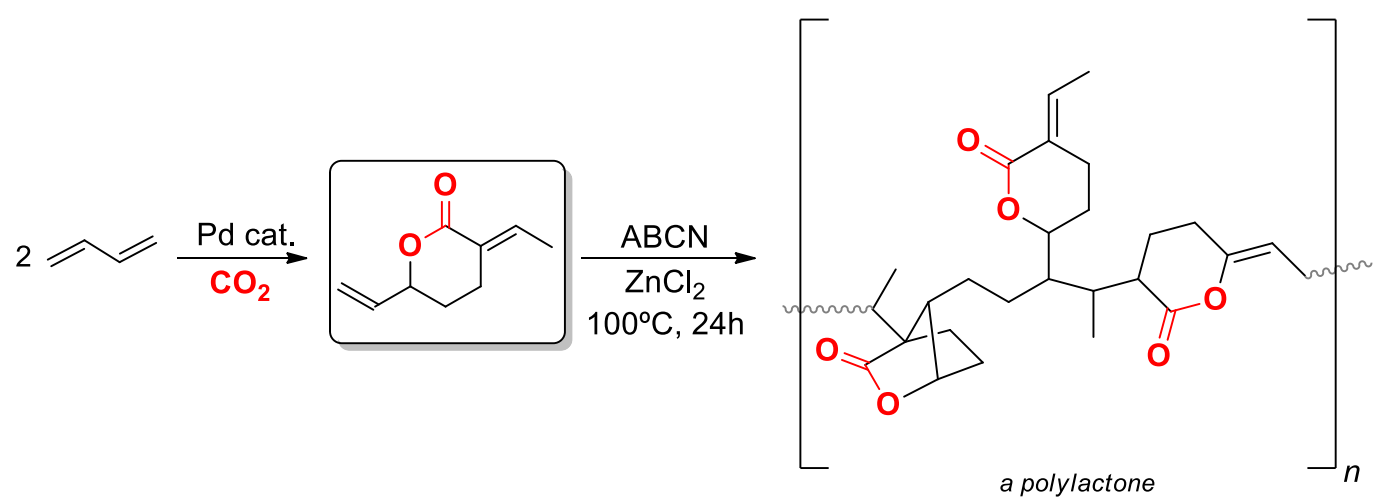

Scheme 22. Nozaki's strategy to create a novel lactone copolymer based on $\mathrm{CO}_{2}$.

Revisiting Inoue's work in the 1970's, the same group also discovered that by using $\mathrm{Ni}(\mathrm{COD})_{2}$-dppb as a catalyst (COD $=1,5$-cyclooctadiene) it is possible to combine two alkyne molecules with $\mathrm{CO}_{2}$ affording six membered lactones, ${ }^{[127]}$ using internal alkynes they were able to obtain more reasonable yields of the lactone products. First $\mathrm{CO}_{2}$ coordinates to electron rich metal centers in a $\eta^{2}$-form (see Figure 7). Alkenes or alkynes in the presence of stoichiometric amounts of the metal- $\mathrm{CO}_{2}$ complex form metallocycles, which are important intermediates in the lactone synthesis. The most widely studied metallocycles are the ones formed with $\mathrm{Ni}(0)$ precursors, the so-called oxa-nickelacycles.

Hoberg et al. ${ }^{[136]}$ published in the 1980 's a series of air-stable complexes where $\mathrm{CO}_{2}$, a suitable $\mathrm{Ni}$ precursor and an unsaturated substrate form a series of metallocyclic complexes incorporating a carboxylate $(\mathrm{O}=\mathrm{C}-\mathrm{O})$ moiety. As illustrated in Scheme 23a, these metallocycles can be useful precursors for other compounds by expanding the ring through incorporation of more ethene molecules, or through ring-opening to form unsaturated carboxylic structures. A clear disadvantage is the lack of true catalytic turnover, an aspect that has recently regained the attention of the scientific communities focusing on the direct coupling of alkenes and $\mathrm{CO}_{2} \cdot{ }^{[137-139]} \mathrm{An}$ oxa-nickelacycle is also an important intermediate in the quinone synthesis from alkynes and $\mathrm{CO}_{2}$ described by Inoue (Scheme 23b). ${ }^{[127]}$ 
Strained rings can be easily carboxylated ${ }^{[140]}$ and the final product can vary in structural nature but all reactions are formally $\mathrm{CO}_{2}$ insertion reactions into $\mathrm{C}-\mathrm{C}$ bonds. A major drawback, however, is that generally the reaction intermediate is a highly stable metallocycle. The lactone formation reaction is promoted by transition metals such as $\mathrm{Ni}$ or Rh but the chemistry has little practical use as there exists a need for stoichiometric amounts of metal with TONs thus rarely exceeding 1 making these processes far from economically acceptable. Recent work ${ }^{[137-139]}$ has indicated that a delicate catalyst design may help to overcome these limitations in the (near) future.

(a)

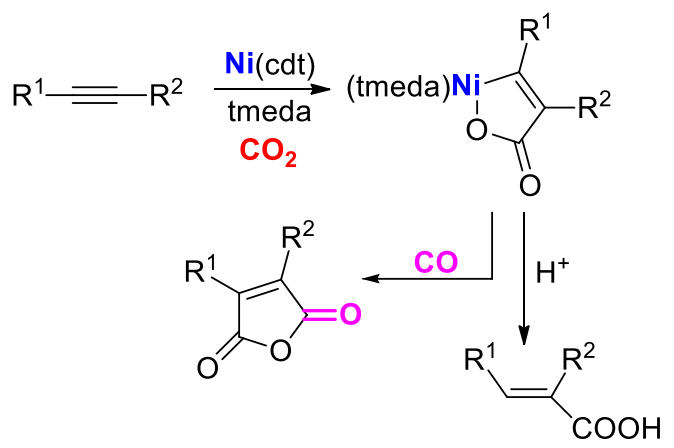

(b)

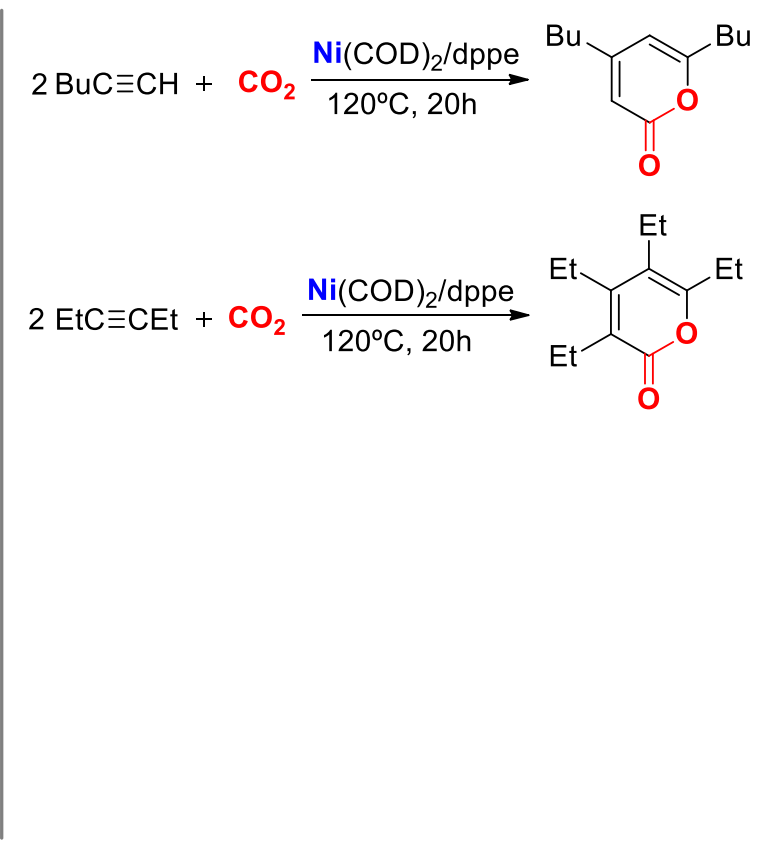

Scheme 23. (a) Hoberg's work on oxa-nickelacycles $($ cdt $=$ cyclododeca-1,5,9triene; $\mathrm{COD}=1,5$-cyclooctadiene; tmeda $=$ tetramethylethylenediamine; $\mathbf{d b u}=\mathbf{1 , 8}$ Diazabicyclo[5.4.0]undec-7-ene), and (b) Inoue's work on quinone synthesis from alkynes.

The ability of $\mathrm{Ni}(0)$ to bind both unsaturated species (i.e., alkenes and alkynes) and $\mathrm{CO}_{2}$ was further demonstrated by Tsuda et al. who prepared bicyclic $\alpha$-pyrones by treating $\alpha$ , $\omega$-diynes under high $\mathrm{CO}_{2}$ pressure ( $\sim 50$ bar) and in the presence of a $\mathrm{Ni}(\mathrm{COD})$-bistrialkylphosphine pre-catalyst $(10 \mathrm{~mol} \%) .{ }^{[141]}$ Tailoring the ligand further, i.e. by using a $N$-heterocyclic carbine ligand (IPr), ${ }^{[142]}$ led to significant improvement in catalyst efficiency and yields ( $>80 \%$ ) of the $\alpha$-pyrone products, and allowed lowering of the metal loading (typically $5 \mathrm{~mol} \%$ ) needed for fast enough turnover and the pressure of $\mathrm{CO}_{2}$ to 1 bar. This process can be considered a formal [2+2+2] cycloaddition reaction between diynes and $\mathrm{CO}_{2}$. In 
Schemea, the proposed mechanism for this reaction shows both a $\mathrm{Ni}(0)$-bis-alkyne- $\mathrm{CO}_{2}$ adduct as well as an oxa-nickelacycle intermediate.

(a)
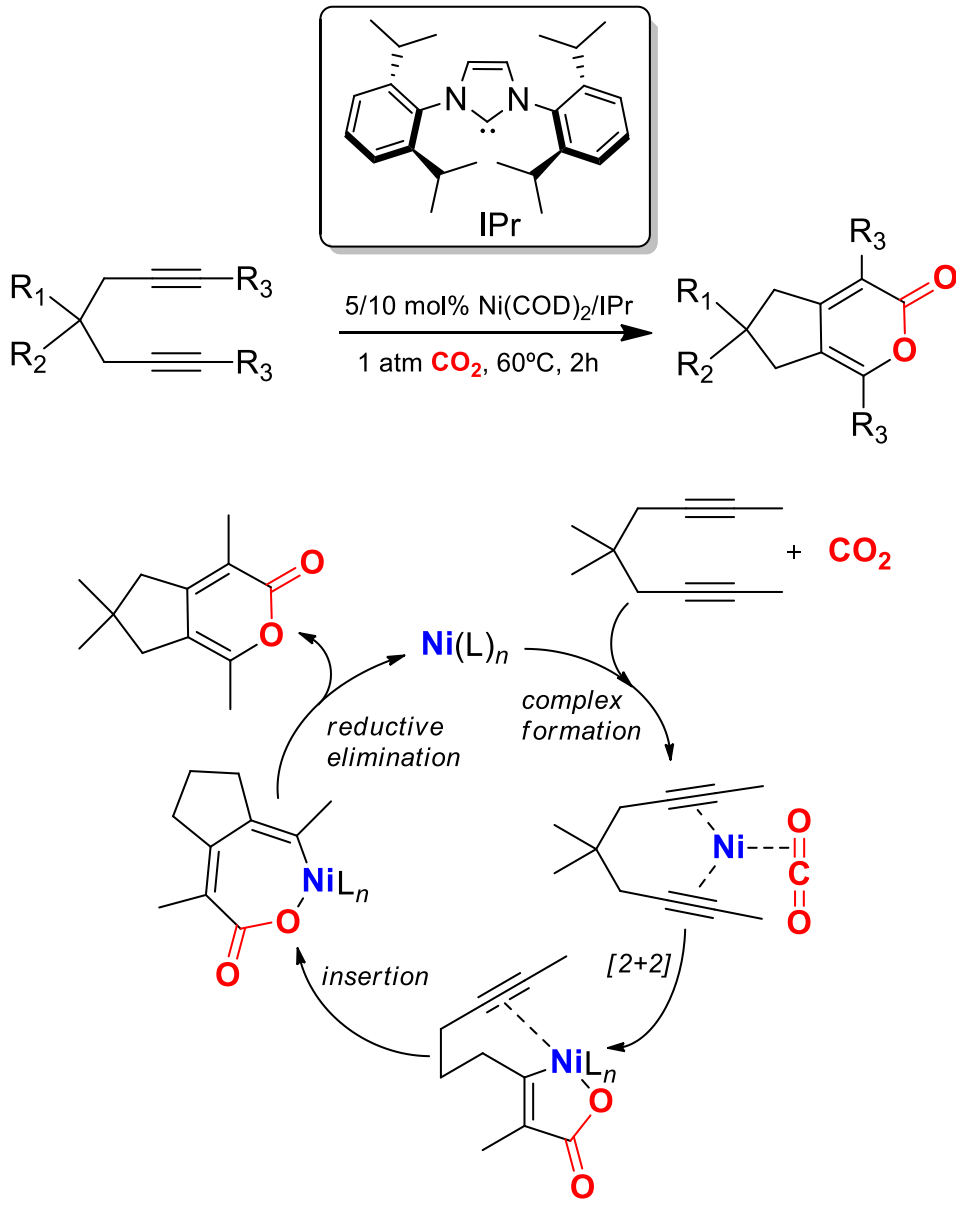

(b)<smiles>COc1ccc(-c2c3c(cc4cc5c(cc24)OCO5)C(=O)OC3)cc1OC</smiles>

Retrochinensin<smiles>COc1cc2c(-c3ccc4c(c3)OCO4)c3c(cc2cc1O)COC3=O</smiles>

Daurinol

Scheme 24. (a) Reaction mechanism proposed by Tekavec et al. for the formation of bicyclic $\alpha$-pyrones from diynes and $\mathrm{CO}_{2}$. (b) Examples of natural products based on the $\alpha$-pyrone core. 
Coupling between two alkynes has found useful applications in synthetic chemistry; it has been applied to the preparation of arylnaphthalene lignan lactones which are valuable natural products (Scheme 24b) with promising anti-cancer and anti-viral properties. In this case the alkynes were present in different precursor molecules and the catalyst used was based on AgI. Anastas et al. ${ }^{[143]}$ envisioned that the cross-coupling reaction between phenylacetylene, $\mathrm{CO}_{2}$ and 3-bromo-1-phenyl-1-propyne would generate the corresponding 1,6-diyne which could then subsequently cyclize to the naphthalene core through a formal $[2+2+2]$ cycloaddition.

Allenes can also be transformed into pyrones (Scheme 25) ${ }^{[144]}$ albeit in lower yields to 4membered lactones, which is the result of a formal [2+2] addition of both cumulenes, $\mathrm{CO}_{2}$ and the allene. In both cases the catalysts employed were based on noble metals such as $\mathrm{Pd}$ and $\mathrm{Rh}$. This [2+2] addition represents the first example of this type of coupling reaction obtained by using $\mathrm{CO}_{2}$ as a reagent. Allenes and $\mathrm{CO}_{2}$ are iso-electronic but the energy gap between the HOMO and LUMO orbitals is large, therefore homo-coupling is energetically favored. In order to make the hetero-coupling reaction possible, optimization of the reaction conditions is essential to control the chemo-selectivity of the reaction. In order to stir the chemo-selectivity towards the 4-membered lactone product, high $\mathrm{CO}_{2}$ pressures combined with low $\mathrm{H}_{2}$ pressures and room temperature conditions are necessary. Despite all the efforts made, only limited yields of the lactone products were obtained and therefore more sophisticated catalysts are required to make this process more attractive.

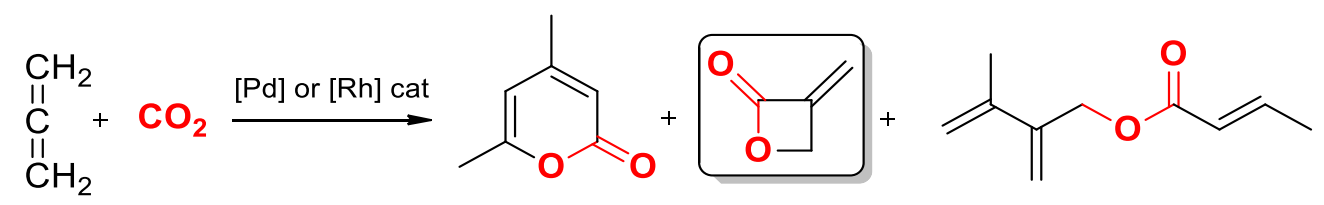

\section{Scheme 25. Possible products derived from the reaction of allenes and $\mathrm{CO}_{2}$.}

\section{Outlook}

This book chapter intends to give an overview of the most recent developments of the catalytic coupling of $\mathrm{CO}_{2}$ with various reaction partners to give cyclized products while maintaining the formal oxidation state of the carbon center. Thus, these reactions can be regarded as non-reductive couplings. Rather than giving a comprehensive overview of all the literature that has appeared over the years, typical examples of each class of coupling reaction involving $\mathrm{CO}_{2}$ as a key reagent have been discussed emphasizing the synthetic merits, and challenges that (still) need to be overcome. These coupling reactions involve the formation of saturated and unsaturated cyclic carbonates, oxazolidinones, imidazolidinones, cyclic ureas, quinazoline derivatives and various lactone based molecules. Despite this wealth of distinct and useful methodology yet developed, there 
still exists a need to expand the use of $\mathrm{CO}_{2}$ as a coupling partner to get access to other types of (functional) molecules where the formal oxidation state of the $\mathrm{CO}_{2}$ coupling partner may change through the catalytic event making the process a formal reductive coupling step. ${ }^{[145]}$ It is not likely that the efforts to develop new and improved catalytic processes will lead to a net reduction of the global $\mathrm{CO}_{2}$ emissions that we are currently facing, but its use as a carbon feed stock that is cheap, renewable, basically non-toxic and readily available in large quantities may help to present a viable carbon feed stock alternative for our fossil fuel based economies. In this respect, research devoted to the design and implementation of modular, selective and highly active catalysts can be regarded as a key strategy towards the increase of sustainable chemical processing in the near future thereby preserving our standard of living and improving where necessary problems associated with raw materials usage, energy consumption and waste management. Undoubtedly, organometallic chemistry will continue to be an important discipline that can contribute both from a fundamental and application point of view providing the knowledge to create our future catalysts required in fine-chemical and bulk chemical synthesis.

\section{References:}

[1] M. Aresta, Carbon Dioxide as Chemical Feedstock, Wiley-VCH, Weinheim, 2010.

[2] M. Peters, B. Köhler, W. Kuckshinrichs, W. Leitner, P. Markewitz, T. E. Müller, ChemSusChem 2011, 4, 1216-1240.

[3] M. Cokoja, C. Bruckmeier, B. Rieger, W. A. Herrmann, F. E. Kühn, Angew. Chem., Int. Ed. 2011, 50, 8510-8537.

[4] R. Martín, A. W. Kleij, ChemSusChem 2011, 4, 1259-1263.

[5] T. Sakakura, J.-C. Choi, H. Yasuda, Chem. Rev. 2007, 107, 2365-2387.

[6] A. Decortes, A. M. Castilla, A. W. Kleij, Angew. Chem. Int. Ed. 2010, 49, 98229837.

[7] M. Mikkelsen, M. Jørgensen, F. C. Krebs, Energy Environ. Sci. 2010, 3, 43-81.

[8] D. J. Darensbourg, Chem. Rev. 2007, 107, 2388-2410.

[9] I. I. F. Boogaerts, S. P. Nolan, Chem. Commun. 2011, 47, 3021-3024.

[10] M. North, R. Pasquale, C. Young, Green Chem. 2010, 12, 1514-1539.

[11] P. P. Pescarmona, M. Taherimehr, Catal. Sci. Technol. 2012, 2, 2169-2187.

[12] C. Maeda, Y. Miyazaki, T. Ema, Catal. Sci. Technol. 2014, 4, 1482-1497.

[13] M. Yoshida, M. Ihara, Chem. Eur. J. 2004, 10, 2886-2893.

[14] (a) T. Sakakura, K. Kohno, Chem. Commun. 2009, 1312-1330; (b) B. Schäffner, F. Schäffner, S. P. Verevkin, A. Börner, Chem. Rev. 2010, 110, 4554-4581.

[15] H. Zhang, H.-B. Liu, J.-M. Yue, Chem. Rev. 2013, 114, 883-898.

[16] Q. He, J. W. O'Brien, K. A. Kitselman, L. E. Tompkins, G. C. T. Curtis, F. M. Kerton, Catal. Sci. Technol. 2014, 4, 1513-1528.

[17] C. J. Whiteoak, A. Nova, F. Maseras, A. W. Kleij, ChemSusChem 2012, 5, 20322038

[18] B. Chatelet, L. Joucla, J.-P. Dutasta, A. Martinez, K. C. Szeto, V. Dufaud, J. Am. Chem. Soc. 2013, 135, 5348-5351. 
[19] Y. Tsutsumi, K. Yamakawa, M. Yoshida, T. Ema, T. Sakai, Org. Lett. 2010, 12, 5728-5731.

[20] C. Qi, J. Ye, W. Zeng, H. Jiang, Adv. Synt. Catal. 2010, 352, 1925-1933.

[21] H. Zhou, W.-Z. Zhang, C.-H. Liu, J.-P. Qu, X.-B. Lu, J. Org. Chem. 2008, 73, 80398044.

[22] W. N. Sit, S. M. Ng, K. Y. Kwong, C. P. Lau, J. Org. Chem. 2005, 70, 8583-8586.

[23] K. M. Doll, S. Z. Erhan, Green Chem. 2005, 7, 849-854.

[24] H. Kawanami, Y. Ikushima, Chem. Commun. 2000, 2089-2090.

[25] H. Sugimoto, S. Inoue, Pure Appl. Chem. 1998, 70, 2365-2369.

[26] N. Ishida, Y. Shimamoto, M. Murakami, Angew. Chem. Int. Ed. 2012, 51, 1175011752.

[27] G. W. Coates, D. R. Moore, Angew. Chem. Int. Ed. 2004, 43, 6618-6639.

[28] M. Ratzenhofer, H. Kisch, Angew. Chem. Int. Ed. Engl. 1980, 19, 317-318.

[29] V. Caló, A. Nacci, A. Monopoli, A. Fanizzi, Org. Lett. 2002, 4, 2561-2563.

[30] K. Kasuga, N. Kabata, T. Kato, T. Sugimori, M. Handa, Inorg. Chim. Acta 1998, 278, 223-225.

[31] K. Kasuga, S. Nagao, T. Fukumoto, M. Handa, Polyhedron 1996, 15, $69-72$.

[32] D. Ji, X. Lu, R. He, Appl. Cat. A: General 2000, 203, 329-333.

[33] M. Taherimehr, S. M. Al-Amsyar, C. J. Whiteoak, A. W. Kleij, P. P. Pescarmona, Green Chem. 2013, 15, 3083-3090.

[34] R. L. Paddock, S. T. Nguyen, J. Am. Chem. Soc. 2001, 123, 11498-11499.

[35] X.-B. Lu, X.-J. Feng, R. He, Appl. Cat. A: General 2002, 234, 25-33.

[36] Y.-M. Shen, W.-L. Duan, M. Shi, J. Org. Chem. 2003, 68, 1559-1562.

[37] D. J. Darensbourg, C. C. Fang, J. L. Rodgers, Organometallics 2004, 23, 924-927.

[38] H. Jing, S. K. Edulji, J. M. Gibbs, C. L. Stern, H. Zhou, S. T. Nguyen, Inorg. Chem. 2004, 43, 4315-4327.

[39] X.-B. Lu, Y.-J. Zhang, K. Jin, L.-M. Luo, H. Wang, J. Catal. 2004, 227, 537-541.

[40] C. J. Whiteoak, G. Salassa, A. W. Kleij, Chem. Soc. Rev. 2012, 41, 622-631.

[41] M. Tokunaga, J. F. Larrow, F. Kakiuchi, E. N. Jacobsen, Science 1997, 277, 936938.

[42] D. J. Darensbourg, A. L. Phelps, Inorg. Chem. 2005, 44, 4622-4629.

[43] D. J. Darensbourg, P. Bottarelli, J. R. Andreatta, Macromolecules 2007, 40, 7727 7729.

[44] D. J. Darensbourg, J. C. Yarbrough, J. Am. Chem. Soc. 2002, 124, 6335-6342.

[45] D. J. Darensbourg, J. C. Yarbrough, C. Ortiz, C. C. Fang, J. Am. Chem. Soc. 2003, $125,7586-7591$

[46] A. Monassier, V. D'Elia, M. Cokoja, H. Dong, J. D. A. Pelletier, J.-M. Basset, F. E. Kühn, ChemCatChem 2013, 5, 1321-1324.

[47] A. Decortes, A. W. Kleij, ChemCatChem 2011, 3, 831-834.

[48] W. Clegg, R. W. Harrington, M. North, R. Pasquale, Chem. Eur. J. 2010, 16, 68286843.

[49] C. J. Whiteoak, E. Martin, E. C. Escudero-Adán, A. W. Kleij, Adv. Synth. Catal. 2013, 355, 2233-2239.

[50] N. Kielland, C. J. Whiteoak, A. W. Kleij, Adv. Synth. Catal. 2013, 355, 2115-2138.

[51] W. Zhang, J. L. Loebach, S. R. Wilson, E. N. Jacobsen, J. Am. Chem. Soc. 1990, $112,2801-2803$. 
[52] R. Irie, K. Noda, Y. Ito, N. Matsumoto, T. Katsuki, Tetrahedron: Asymm. 1990, 2 , 481-494.

[53] E. N. Jacobsen, Acc. Chem. Res. 2000, 33, 421-431.

[54] M. Aresta, A. DiBenedetto, L. Gianfrate, C. Pastore, Appl. Catal. A: General 2003, 255, 5-11.

[55] X.-B. Lu, B. Liang, Y.-J. Zhang, Y.-Z. Tian, Y.-M. Wang, C.-X. Bai, H. Wang, R. Zhang, J. Am. Chem. Soc. 2004, 126, 3732-3733.

[56] L. Jin, Y. Huang, H. Jing, T. Chang, P. Yan, Tetrahedron: Asymm. 2008, 19, 19471953.

[57] V. Vincens, A. L. Borgne, N. Spassky, Makromol. Chem.-Rapid 1989, 10, 623628.

[58] X.-B. Lu, R. He, C.-X. Bai, J. Mol. Catal. A: Chem. 2002, 186, 1-11.

[59] X.-B. Lu, Y. J. Zhang, B. Liang, H. Wang, J. Mol. Catal. A: Chem. 2004, 210, 3134.

[60] T. R. J. Achard, L. A. Clutterbuck, M. North, Synlett. 2005, 1828-1847.

[61] F. Li, C. Xia, L. Xu, W. Sun, G. Chen, Chem. Commun. 2003, 2042-2043.

[62] R. Srivastava, T. H. Bennur, D. Srinivas, J. Mol. Catal. A: Chem. 2005, 226, 199205.

[63] M. L. Man, K. C. Lam, W. N. Sit, S. M. Ng, Z. Zhou, Z. Lin, C. P. Lau, Chem. Eur. J. 2006, 12, 1004-1015.

[64] D. J. Darensbourg, A. Horn Jr, A. I. Moncada, Green Chem. 2010, 12, 1376-1379.

[65] A. Decortes, M. Martínez Belmonte, J. Benet-Buchholz, A. W. Kleij, Chem. Commun. 2010, 46, 4580-4582.

[66] F. Castro-Gómez, G. Salassa, A. W. Kleij, C. Bo, Chem. Eur. J. 2013, 19, 62896298.

[67] R. M. Haak, S. J. Wezenberg, A. W. Kleij, Chem. Commun. 2010, 46, 2713-2723.

[68] W.-M. Ren, Z.-W. Liu, Y.-Q. Wen, R. Zhang, X.-B. Lu, J. Am. Chem. Soc. 2009, $131,11509-11518$.

[69] For a recent example see: T. Ema, Y. Miyazaki, S. Koyama, Y. Yano, T. Sakai, Chem. Commun. 2012, 48, 4489-4491.

[70] J. Melendez, M. North, P. Villuendas, Chem. Commun. 2009, 2577-2579.

[71] J. Meléndez, M. North, R. Pasquale, Eur. J. Inorg. Chem. 2007, 3323-3326.

[72] M. North, B. Wang, C. Young, Energy Environ. Sci. 2011, 4, 4163-4170.

[73] D. Tian, B. Liu, Q. Gan, H. Li, D. J. Darensbourg, ACS Catalysis 2012, 2, 20292035.

[74] Y. Liu, W.-M. Ren, J. Liu, X.-B. Lu, Angew. Chem. Int. Ed. 2013, 52, 11594-11598.

[75] D. J. Darensbourg, W.-C. Chung, S. J. Wilson, ACS Catalysis 2013, 3, 3050-3057.

[76] R. Luo, X. Zhou, S. Chen, Y. Li, L. Zhou, H. Ji, Green Chem. 2014, 16, 1496-1506.

[77] A. Buchard, M. R. Kember, K. G. Sandeman, C. K. Williams, Chem. Commun. 2011, 47, 212-214.

[78] M. V. Escárcega-Bobadilla, M. Martínez Belmonte, E. Martin, E. C. EscuderoAdán, A. W. Kleij, Chem. Eur. J. 2013, 19, 2641-2648.

[79] T. Chang, L. Jin, H. Jing, ChemCatChem 2009, 1, 379-383.

[80] P. G. Jessop, B. Subramaniam, Chem. Rev. 2007, 107, 2666-2694. 
[81] S. Minakata, I. Sasaki, T. Ide, Angew. Chem. Int. Ed. 2010, 49, 1309-1311.

[82] J. Wu, J. A. Kozak, F. Simeon, T. A. Hatton, T. F. Jamison, Chem. Sci. 2014, 5, 1227-1231.

[83] X. Yang, J. Wu, X. Mao, T. F. Jamison, T. A. Hatton, Chem. Commun. 2014, 50, 3245-3248.

[84] W. Yamada, Y. Sugawara, H. M. Cheng, T. Ikeno, T. Yamada, Eur. J. Org. Chem. 2007, 2604-2607.

[85] S. Yoshida, K. Fukui, S. Kikuchi, T. Yamada, Chem. Lett. 2009, 38, 786-787.

[86] M. Costa, G. P. Chiusoli, M. Rizzardi, Chem. Commun. 1996, 1699-1700.

[87] N. D. Ca, B. Gabriele, G. Ruffolo, L. Veltri, T. Zanetta, M. Costa, Adv. Synth. Catal. 2011, 353, 133-146.

[88] S. Yoshida, K. Fukui, S. Kikuchi, T. Yamada, J. Am. Chem. Soc. 2010, 132, 40724073.

[89] X. Tang, C. Qi, H. He, H. Jiang, Y. Ren, G. Yuan, Adv. Synth. Catal. 2013, 355, 2019-2028.

[90] D. Diekema, R. Jones, Drugs 2000, 59, 7-16.

[91] N. Pandit, R. K. Singla, B. Shrivastava, Indo Global J. Pharmaceut. Sci. 2012, 2, 245-249.

[92] K. J. Shaw, M. R. Barbachyn, Ann. N.Y. Acad. Sci. 2011, 1241, 48-70.

[93] K. Michalska, I. Karpiuk, M. Król, S. Tyski, Bioorg. Med. Chem. 2013, 21, 577591.

[94] G. Zappia, G. Cancelliere, E. Gacs-Baitz, G. Delle Monache, D. Misiti, L. Nevola, B. Botta, Curr. Org. Synth. 2007, 4, 238-309.

[95] D. A. Evans, J. M. Takacs, L. R. McGee, M. D. Ennis, D. J. Mathre, J. Bartroli, Pure Appl. Chem. 1981, 53, 1109-1127.

[96] R. Green, J. Peed, J. E. Taylor, R. A. R. Blackburn, S. D. Bull, Nat. Protocols 2013, 8, 1890-1906.

[97] For a recent example see: D. B. Nale, S. Rana, K. Parida, B. M. Bhanage, Appl. Catal. A: General 2014, 469, 340-349.

[98] M. P. Sibi, P. K. Deshpande, J. Ji, Tetrahedron Lett. 1995, 36, 8965-8968.

[99] H.-P. Buchstaller, J. Comb. Chem. 2003, 5, 789-793.

[100] T. Mizuno, J. Takahashi, A. Ogawa, Tetrahedron 2002, 58, 7805-7808.

[101] S. Pulla, C. M. Felton, P. Ramidi, Y. Gartia, N. Ali, U. B. Nasini, A. Ghosh, J. $\mathrm{CO}_{2}$ Utiliz. 2013, 2, 49-57.

[102] P. Tascedda, E. Dunach, Chem. Commun. 2000, 449-450.

[103] A. Sudo, Y. Morioka, E. Koizumi, F. Sanda, T. Endo, Tetrahedron Lett. 2003, 44, 7889-7891.

[104] M. T. Hancock, A. R. Pinhas, Tetrahedron Lett. 2003, 44, 5457-5460.

[105] A. W. Miller, S. T. Nguyen, Org. Lett. 2004, 6, 2301-2304.

[106] Y. Wu, L.-N. He, Y. Du, J.-Q. Wang, C.-X. Miao, W. Li, Tetrahedron 2009, 65, 6204-6210.

[107] F. Fontana, C. C. Chen, V. K. Aggarwal, Org. Lett. 2011, 13, 3454-3457.

[108] K. Soga, S. Hosoda, H. Nakamura, S. Ikeda, J. Chem. Soc., Chem. Commun. 1976, 617-617. 
[109] H. Kawanami, Y. Ikushima, Tetrahedron Lett. 2002, 43, 3841-3844.

[110] J. Seayad, A. M. Seayad, J. K. P. Ng, C. L. L. Chai, ChemCatChem 2012, 4, 774777.

[111] Y. Du, Y. Wu, A.-H. Liu, L.-N. He, J. Org. Chem. 2008, 73, 4709-4712.

[112] C. Phung, R. M. Ulrich, M. Ibrahim, N. T. G. Tighe, D. L. Lieberman, A. R. Pinhas, Green Chem. 2011, 13, 3224-3229.

[113] R. Nomura, H. Matsuda, A. Baba, M. Kori, S. Ogawa, Ind. Eng. Chem. Prod. Res. Dev. 1985, 24, 239-242.

[114] S. Pulla, C. M. Felton, Y. Gartia, P. Ramidi, A. Ghosh, ACS Sust. Chem. Eng. 2013, 1, 309-312.

[115] C. J. Dinsmore, S. P. Mercer, Org. Lett. 2004, 6, 2885-2888.

[116] M. Kodaka, T. Tomohiro, H. Okuno, J. Chem. Soc., Chem. Commun. 1993, 81-82.

[117] T.-A. Mitsudo, Y. Hori, Y. Yamakawa, Y. Watanabe, Tetrahedron Lett. 1987, 28, 4417-4418.

[118] G. P. Chiusoli, M. Costa, B. Gabriele, G. Salerno, J. Mol. Cat: Chem. 1999, 143, 297-310.

[119] M. Shi, Y.-M. Shen, J. Org. Chem. 2002, 67, 16-21.

[120] Meessen, J. H.; Petersen, H. (2005), "Urea", Ullmann's Encyclopedia of Industrial Chemistry, Weinheim: Wiley-VCH, doi:10.1002/14356007.a27 333

[121] T. Mizuno, N. Okamoto, T. Ito, T. Miyata, Tetrahedron Lett. 2000, 41, 1051-1053.

[122] Y. P. Patil, P. J. Tambade, S. R. Jagtap, B. M. Bhanage, Green Chem. Lett. Rev. 2008, $1,127-132$.

[123] T. Kimura, K. Kamata, N. Mizuno, Angew. Chem. Int. Ed. 2012, 51, 6700-6703.

[124] T. Kimura, H. Sunaba, K. Kamata, N. Mizuno, Inorg. Chem. 2012, 51, 1300113008.

[125] S.-I. Fujita, M. Tanaka, M. Arai, Catal. Sci. Technol. 2014, 4, 1563-1569.

[126] M. Aresta, C. F. Nobile, V. G. Albano, E. Forni, M. Manassero, J. Chem. Soc., Chem. Commun. 1975, 636-637.

[127] Y. Inoue, Y. Itoh, H. Hashimoto, Chem. Lett. 1977, 855-856.

[128] Y. Inoue, Y. Itoh, H. Hashimoto, Chem. Lett. 1978, 633-634.

[129] Y. Inoue, T. Hibi, M. Satake, H. Hashimoto, J. Chem. Soc., Chem. Commun. 1979, 982-982.

[130] Y. Sasaki, Y. Inoue, H. Hashimoto, J. Chem. Soc., Chem. Commun. 1976, 605-606.

[131] A. Musco, C. Perego, V. Tartiari, Inorg. Chim. Acta 1978, 28, L147-L148.

[132] A. Behr, R. He, K. D. Juszak, C. Krueger, Y. H. Tsay, Chem. Ber. 1986, 119, 9911015.

[133] A. Behr, P. Bahke, M. Becker, Chem. Ing. Tech. 2004, 76, 1828-1832.

[134] A. Behr, M. Heite, Chem.-Ing.-Tech. 2000, 72, 58-61.

[135] R. Nakano, S. Ito, K. Nozaki, Nat. Chem. 2014, 6, 325-331.

[136] H. Hoberg, Y. Peres, C. Krueger, Y. H. Tsay, Angew. Chem. 1987, 99, 799-800.

[137] N. Huguet, I. Jevtovikj, A. Gordillo, M. L. Lejkowski, R. Lindner, M. Bru, A. Y. Khalimon, F. Rominger, S. A. Schunk, P. Hofmann, M. Limbach, Chem. Eur. J. 2014, DOI: $10.1002 /$ chem.201405528. 
[138] C. Hendriksen, E. A. Pidko, G. Yang, B. Schäffner, D. Vogt, Chem. Eur. J. 2014, DOI: $10.1002 /$ chem.201404082.

[139] M. L. Lejkowski, R. Lindner, T. Kageyama, G. É. Bódizs, P. N. Plessow, I. B. Müller, A. Schäfer, F. Rominger, P. Hofmann, C. Futter, S. A. Schunk, M. Limbach, Chem. Eur. J. 2012, 18, 14017-14025.

[140] A. Behr, G. Thelen, C1 Mol. Chem. 1984, 1, 137-153.

[141] T. Tsuda, S. Morikawa, R. Sumiya, T. Saegusa, J. Org. Chem. 1988, 53, 3140-3145.

[142] J. Louie, J. E. Gibby, M. V. Farnworth, T. N. Tekavec, J. Am. Chem. Soc. 2002, 124, 15188-15189.

[143] P. Foley, N. Eghbali, P. T. Anastas, J. Nat. Prod. 2010, 73, 811-813.

[144] A. Doehring, P. W. Jolly, Tetrahedron Lett. 1980, 21, 3021-3024.

[145] See for a recent example: C. Das Neves Gomes, O. Jacquet, C. Villiers, P. Thuéry, M. Ephritikhine, T. Cantat, Angew. Chem. Int. Ed. 2012, 51, 187-190. 